\title{
Perceived Burdensomeness, Thwarted Belongingness and Acquired Capability for Suicide: Suicidal Risk Factors in an Incarcerated Population
}

\author{
Sarra Nazem \\ West Virginia University
}

Follow this and additional works at: https://researchrepository.wvu.edu/etd

\section{Recommended Citation}

Nazem, Sarra, "Perceived Burdensomeness, Thwarted Belongingness and Acquired Capability for Suicide: Suicidal Risk Factors in an Incarcerated Population" (2013). Graduate Theses, Dissertations, and Problem Reports. 161.

https://researchrepository.wvu.edu/etd/161

This Dissertation is protected by copyright and/or related rights. It has been brought to you by the The Research Repository @ WVU with permission from the rights-holder(s). You are free to use this Dissertation in any way that is permitted by the copyright and related rights legislation that applies to your use. For other uses you must obtain permission from the rights-holder(s) directly, unless additional rights are indicated by a Creative Commons license in the record and/ or on the work itself. This Dissertation has been accepted for inclusion in WVU Graduate Theses, Dissertations, and Problem Reports collection by an authorized administrator of The Research Repository @ WVU.

For more information, please contact researchrepository@mail.wvu.edu. 
Perceived Burdensomeness, Thwarted Belongingness and Acquired Capability for Suicide: Suicidal Risk Factors in an Incarcerated Population

\section{Sarra Nazem, M.S.}

Dissertation submitted to the Eberly College of Arts and Sciences at West Virginia University in partial fulfillment of the requirements for the degree of

Doctor of Philosophy

in Psychology

Amy Fiske, Ph.D., C.B.S.M, Chair

Edward Baker, Ph.D.

Barry Edelstein, Ph.D.

William Fremouw, Ph.D., A.B.P.P.

Amy Gentzler, Ph.D.

Department of Psychology

Morgantown, West Virginia

2013

Keywords: Suicidal behavior, Incarceration, Interpersonal theory of suicide Copyright 2013 Sarra Nazem 


\begin{abstract}
Perceived Burdensomeness, Thwarted Belongingness and Acquired Capability for Suicide: Suicidal Risk Factors in an Incarcerated Population
\end{abstract}

\title{
Sarra Nazem, M.S.
}

Suicide is one of the leading causes of death in incarcerated individuals. Previous research suggests that prior suicidal behaviors, history of substance abuse/dependence, and depressive symptoms are common risk factors associated with death by suicide in incarcerated populations. Additionally, offenders who have committed violent crimes, are incarcerated in higher security institutions, and have longer sentences are also at increased risk for suicide. Although research has identified risk factors for suicidal behaviors, there has been very little theory-driven research on suicidal behaviors in incarcerated populations. Joiner's interpersonal theory of suicide (Joiner, 2005; Van Orden et al., 2010) may be an especially promising tool for use in studying suicidal behaviors in incarcerated individuals. The current study assessed whether federally incarcerated individuals $(n=114)$ differed from community controls $(n=96)$ in levels of perceived burdensomeness, thwarted belongingness, and acquired capability for suicide, components of Joiner's interpersonal theory. Incarcerated individuals did not report greater levels of perceived burdensomeness, thwarted belongingness, exposure to painful and provocative events, and acquired capability for suicide compared to community controls. Findings from an exploratory factor analysis of painful and provocative events in incarcerated individuals suggest that when controlling for other significant factors, legal painful and provocative events were independently predictive of acquired capability for suicide. Further research on suicidal risk factors in incarcerated populations is recommended and may prove especially useful in improving risk identification programs used in incarceration settings. 


\section{Acknowledgements}

The completion of this project would not have been possible without the support of several individuals. First, I would like to thank my advisor, Amy Fiske, Ph.D., for her guidance on this dissertation study and her mentorship throughout my graduate training. I would also like to acknowledge my committee members, Edward Baker, Ph.D., Barry Edelstein, Ph.D., William Fremouw, Ph.D., A.B.P.P., and Amy Gentzler, Ph.D., for their helpful comments, time and encouragement. I am especially appreciative for all of the support and assistance that Dr. Baker has provided over the past several years; this project would not have been possible without him. I would also like to recognize members of the Mental Health and Aging Lab for their support and I would like to acknowledge the participants of this study who have helped make this research possible. Finally, I would also like to thank my family, especially my parents, and friends for their encouragement, support, and love. 


\section{Table of Contents}

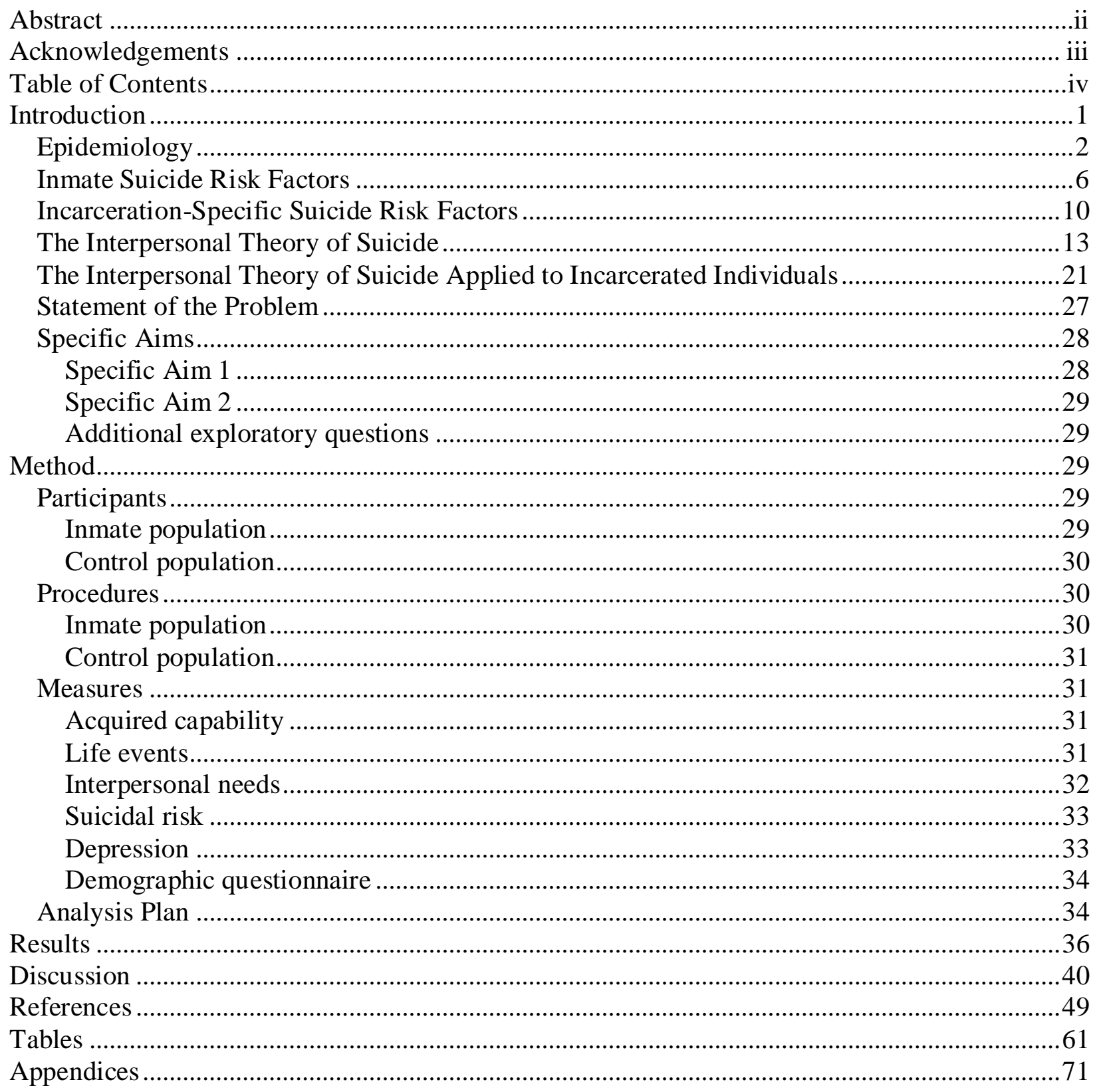


Perceived Burdensomeness, Thwarted Belongingness and Acquired Capability for Suicide: Suicidal Risk Factors in an Incarcerated Population

Suicide remains one of the leading causes of preventable death in incarcerated individuals (Way, Miraglia, Sawyer, Beer, \& Eddy, 2005). Estimates suggest that federal prison suicide rates are about 14/100,000 (United States Federal Bureau of Prisons, 2011), whereas suicide rates for jails and state prisons are estimated to be much higher. Over the past twenty years, research has focused on the identification of risk factors for suicidal behaviors in incarcerated populations. Although these studies have identified several inmate- and incarceration-specific factors that are associated with suicidal behaviors, existing prison screening procedures are still criticized as neither sensitive nor specific enough for adequately assessing suicide risk in incarcerated populations (Mitichison, Rix, Renvoize, \& Schweiger, 1994). Additionally, despite suicide being a leading cause of incarceration-related deaths, the prediction of suicide remains a difficult task as suicide is a relatively rare event (Perry, Marandos, Coulton, \& Johnson, 2010). Theories to explain suicidal behaviors in incarcerated populations have infrequently been used to better understand why incarcerated individuals are at increased risk for suicidal behaviors. Consequently, a variety of risk factors have been identified, but no coherent theory guides the conceptualization of risk.

The current study seeks to better understand risk factors that may be associated with suicidal behavior in an incarcerated population and is guided by a theory that may improve the conceptualization of suicidal risk in incarcerated populations. After reviewing the epidemiology of suicide in incarcerated populations, the most prominent risk factors that have been identified as correlates of suicide in incarcerated samples will be covered. Next, Joiner's interpersonal theory of suicide (2005) will be introduced as a tool to understand and conceptualize why 
incarcerated individuals may be at increased risk for suicidal behaviors. Empirical evidence and conceptual rationale for Joiner's theory in incarcerated populations, including a preliminary study using some of the theory's components in an incarcerated population, will be discussed.

\section{Epidemiology}

United States federal prisons. Since 1990, a total of 274 United States federal inmates died by suicide (United States Federal Bureau of Prisons, 2011). The rate of suicide has fluctuated over the past two decades, with rates recorded as low as 5/100,000 and as high as 19/100,000, with an average suicide rate of 10.8/100,000 between 1990 and 2011. Over the same time period, the average rate of suicide in the general United States population was 10.96/100,000. In 2010, the most recent national suicide data available, the suicide rate for the general population was 12.4/100,000 (McIntosh \& Drapeau, 2012) whereas the United State federal inmate suicide rate for the 2010 fiscal year was 5/100,000 (United States Federal Bureau of Prisons, 2011).

Comparisons between the federal and general population suicide rates, however, are only provided as rough estimates, as the general population suicide rate includes both genders, whereas federal prison populations are at least $90 \%$ male (Bureau of Prisons, 2011). For example, the 2010 general population suicide rate was 20.0/100,000 for males compared to $5.2 / 100,000$ for females, suggesting that comparisons between federal prison suicide rates, which are predominately male in their composition, may be more accurately compared to male general population rates. Thus, it may be more accurate to say that the federal inmate suicide rate of $5 / 100,000$ in the 2010 fiscal year fell below the male general population suicide rate of $20 / 100,000$ in 2010 . 
Furthermore, determining suicide rates by race/ethnicity and age group are also important considerations not reflected in the overall general population rate to federal rate comparison provided above. Currently, a little over half of federal inmates are White (58.6\%) and 37.9\% are Black (Bureau of Prisons, 2011). Additionally, 34.2\% of the federal population is Hispanic (Bureau of Prisons, 2011). General population suicide rates in 2010 differed by race and ethnicity; the highest rates were identified for non-Hispanic Caucasians (McIntosh \& Drapeau, 2012) again suggesting that demographic characteristics should be considered when comparing rates across populations. Furthermore, general population suicide rates in 2010 varied by age group (15-24 year olds: 10.5, 25-34 year olds: 14.0, 35-44 year olds: 16.0, 45-54 year olds: 19.6, and 55-64 year olds: 17.5), indicating that federal inmate suicide rate comparisons may vary dramatically based on specific age classifications (note: current average age of federal inmates is 39 years; Bureau of Prisons, 2011). To summarize, based on crude suicide rates using general demographic averages (e.g., 39 year-old male as an average federal inmate), the United States federal inmate suicide rates generally seem to be lower than general population suicide rates when using similar demographic rate comparisons, especially when examining the most recent suicide data available. Regardless of the rate and comparison figures, suicide is still one of the leading causes of preventable death in incarcerated individuals (Way et al., 2005).

In contrast to the relatively few suicides since 1990 , there have been a total of 12,573 suicide attempts in United States federal correctional institutions (United States Federal Bureau of Prisons, 2011). The ratio (46:1) between deaths by suicide (274) and suicide attempts $(12,573)$ is consistent with findings from the general population, where suicide attempts are more common than deaths by suicide (McIntosh \& Drapeau, 2012). Although no official United States data are collected, estimates suggest that the general population ratio of attempts to suicides is 
25:1 (American Association of Suicidology, 2007; McIntosh \& Drapeau, 2012), though an 11:1 ratio has also been suggested (National Institute of Mental Health, 2011). This figure varies dramatically by age, however, with estimates suggesting suicide attempt to suicide ratios of 100200:1 for young and 4:1 for older adults (McIntosh \& Drapeau, 2012). Without taking into account potential age effects, it appears as though the federal suicide attempt to suicide ratio is higher than the general population attempt to suicide ratio.

The suicide attempt rate in United States federal correctional institutions has increased over the past two decades, with the rate averaging 434/100,000 between 1990 and 1999 and 477/100,000 between 2000 and 2010 (United States Federal Bureau of Prisons, 2011). Specifically, suicide attempts have been rising since 2005, from a total of 766 attempts in 1995 (rate: 410/100,000) to 1,162 attempts in 2010 (rate: 607/100,000). It could be possible that the increase in attempts over the past two decades may be due to improved reporting or better identification procedures and not actual attempt increases. Regardless, as the data stand currently, the federal inmate suicide attempt rate appears quite high, especially given that these attempts take place in highly controlled settings.

United States jail and state prisons. According to 2002 data from the Bureau of Justice Statistics, suicide was the third leading cause of death for both jail and state prison inmates (Mumola, 2005). The suicide rate in jails $(47 / 100,000)$ was over three times greater than the suicide rate in state prisons $(14 / 100,000)$. Rates also differed by offense status, such that inmates convicted of violent offenses in both jail $(92 / 100,000)$ and state prisons $(19 / 100,000)$ had suicide rates twice that of non-violent offender jail $(31 / 100,000)$ and state prison inmates $(9 / 100,000)$. Mortality rates due to suicide have decreased over the past 20 years, similar to the declines seen in the federal system institutions. White inmates, between 2000-2002 at jails and state prisons, 
were more likely to die by suicide than Hispanic inmates, and Hispanic inmates were more likely to die by suicide than Black inmates. Over the same time period, increasing age was associated with increased suicide rate for jails but not for state prisons. More recent data from 2006 found the jail suicide rate to be $38 / 100,000$, a rate approximately three times greater than that of the general population (Hayes, 2011).

International prisons. Although rates of suicide in incarcerated individuals outside of the United States have also seen general downward trends over the past several decades, the rates of suicide in international prisons still remains quite high, and often higher than United States rates. For example, a study of England and Wales custody deaths reported the two year rate of suicide in prison to be 133 per 100,000 inmates (Shaw, Baker, Hunt, Moloney, \& Appleby, 2004) reflecting the finding that the suicide rates of prisoners in these countries is approximately five times higher than the general population rate (Fazel, Benning, Danesh, 2005). In Canada, the suicide rate for men incarcerated in the federal system was about four times higher than the national Canadian rate (Laishes, 1997). These findings support a recent international effort aimed at identifying the prison suicide rates between countries. Fazel, Grann, Kling, \& Hawton (2011) collected data on suicides and undetermined deaths in 12 countries and found that for incarcerated men, prison suicide rates were at least three times higher than the general population suicide rate. International prison suicide rates, then, seem to mirror, and to a large extent, may be more amplified than national suicide prison rates.

Suicide ideation. A large percentage of the research on inmate suicidal behavior has been devoted to documenting the suicide rate in prisons rather than the prevalence of suicidal ideation in incarcerated individuals. The literature that has specifically examined suicidal ideation in inmates, without a priori selecting samples based on prior suicidal behavior, has 
found that suicidal ideation may be common in incarcerated populations. Two studies conducted on Italian inmates found suicide ideation to be common, with $40 \%$ (Sarchiapone et al., 2009) and $42 \%$ (Carli et al., 2010) of inmates reporting lifetime suicidal ideation. A study by Way and colleagues (2005) found a slightly lower rate of suicidal ideation in inmates, with about $34 \%$ endorsing suicidal ideation. These studies, however, lacked respective control groups. In a study comparing England and Wales prisoners with community controls, Jenkins et al. (2005) found that the lifetime prevalence of suicidal thoughts in prisoners was three times more common in inmates than controls. Furthermore, the one-year prevalence of ideation was 5-12 times more common in inmates than controls and the one-week prevalence was 20 times more likely in inmates than controls. Although there has not been an overabundance of research on suicidal ideation in inmates, it does appear that a large percentage of inmates may have the desire to die by suicide.

\section{Inmate Suicide Risk Factors}

Recent research suggests that inmates may constitute a section of the population that is already characterized by a greater number of risk factors for suicidal behavior (Konrad, 2001; Way et al., 2005). For example, incarcerated individuals are more likely to be male and unmarried, both well-known risk factors for suicidal behavior (Blaauw, Kerkhof, \& Hayes, 2005; Charles, Abram, McClelland, \& Teplin, 2003; Felthous, 2011). Furthermore, results from 62 surveys from 12 countries on incarcerated individuals found that about one in seven prisoners in western countries had psychotic illnesses or major depression, both factors associated with increased suicidal risk (Fazel \& Danesh, 2002). Whether incarcerated individuals come to prison with a set of factors that already places them at higher risk for suicidal behaviors or whether incarcerated individuals develop new psychopathology or encounter new experiences that then 
constitute new risk for suicidal behavior, is unclear. Regardless of the timing, however, there do appear to be common risk factors that characterize the suicidal inmate.

The most predictive risk factor associated with death by suicide is previous suicide attempts (Lewinsohn, Rohde, \& Seeley, 1994). Several studies of inmate populations have found supporting evidence that inmates who have died by suicide had a history of prior suicidal behavior (Daniel \& Fleming, 2005; He, Felthous, Holzer, Nathan, \& Veasey, 2001). A review of 19 studies suggests that around half of all inmates who died by suicide had a history of suicide attempts (Blaauw et al., 2005) supporting the epidemiological evidence of the high attempt to completion ratio in federal prison inmates described earlier. Similarly, psychological autopsy evidence suggested that $52 \%$ of suicide cases from New York state prisons had a prior history of suicide attempts (Way et al., 2005). A total of $68 \%$ of South Wales prison suicides had a documented history of self-harm (O’Driscoll, Samuels, \& Zacka, 2007) and similarly 43\% of suicide cases in England and Wales had a history of deliberate self-harm (Dooley, 1990). The association between previous suicidal behavior and suicide is consistent with literature that has identified prior suicide attempts as a predictive risk factor for suicide in other non-incarcerated populations (Moscicki, 1995; Rihmer, Belso, \& Kiss, 2002). For example, in a 20-year prospective study of psychiatric outpatients, Brown and colleagues (2000) found that previous suicide attempts were associated with over three times increased risk for suicide in statistical models controlling for other common suicide risk factors like major depressive disorder, age, psychiatric hospitalization, and unemployment. Similarly, Joiner et al. (2005) found that past suicidal behavior was a predictive factor for later suicidal behavior across different samples and age groups even after controlling for hopelessness and Axis I and II diagnoses. 
In addition to prior suicidal behaviors, substance abuse or dependence is also a common risk factor for suicide in incarcerated individuals. Using a national clinical survey based on a two-year sample of inmate suicides, Shaw et al. (2004) found that a diagnosis of drug dependence was the most common primary diagnosis in inmates who had died by suicide. Between 1971 and 1976, Novick and Remmlinger (1978) found that $69 \%$ of suicide cases had a history of drug or alcohol abuse. Illicit drug use was reported by $52 \%$, alcohol abuse by $8 \%$ and a combination of drugs and alcohol by $10 \%$ (Novick \& Remmlinger, 1978). Furthermore, in New York state prison suicide cases, substance abuse history was present in $95 \%$ of cases (Way et al., 2005) and over a ten-year period, $49 \%$ of North Wales suicide cases had a documented diagnosis of substance abuse in prison medical files (O’Driscoll et al., 2007). Although these studies used a variety of ways to measure substance abuse or dependence (i.e., prison record, psychiatric contact), all point to an association between substance use and increased risk for suicide which has also been demonstrated in non-incarcerated populations (Cavanagh, Carson, Sharpe, \& Lawrie, 2003). In a review of the relation between alcoholism and suicidal behavior, Sher (2006) suggests that individuals who abuse alcohol are at increased risk for death by suicide and this increased risk may be especially pronounced in individuals who are also depressed (Sher, Oquendo, Mann, 2001). Lifetime risk for death by suicide in non-incarcerated individuals who have had histories of substance dependence have ranged between $2 \%$ to as high as $18 \%$ (Roy \& Linnoila, 1986; Murphy \& Wetzel, 1990) and have been found to be associated with about six times increased risk for suicide (Harris \& Barraclough, 1997).

Some studies have found evidence in support of affective symptoms increasing suicide risk, whereas others have not found evidence for such an association in incarcerated individuals. After comparing a sample of inmates with a history of prior self-harm with a sample of inmates 
with no history of self-harm, Palmer and Connelly (2005) found that inmates with previous selfharm behaviors were significantly more likely to have high scores on hopelessness, depression, and suicidal ideation than those inmates with no history. Research on actual suicide cases, however, presents a somewhat conflicting view. For example, in a study comparing suicide cases with general mental health cases, Way et al. (2005) found that only $9 \%$ of suicide cases had a major depression or bipolar diagnosis whereas $21 \%$ of mental health cases did. Similarly, only $11 \%$ of suicide cases in North South Wales prisons had a diagnosis of major depression documented in the medical file (O’Driscoll et al., 2007). In contrast, He et al. (2001) found that $60 \%$ of individuals who died by suicide had a history of psychiatric diagnosis, of which mood disorders were the most common diagnosis. In a meta-analysis of 109 samples, Fazel and Seewald (2012) found a pooled prevalence of major depression to be $10.2 \%$ in male prisoners. Studies in non-incarcerated populations suggest a stronger association between affective disorders and suicide behaviors (Cavanagh et al., 2003). For example, after reviewing thirtythree studies from several countries, Harris and Barraclough (1997) found that major depressive disorder was on average associated with a 20 times increased suicide risk. This association has also been supported in other reviews, where major depressive disorder is the most common diagnosis in individuals who have died by suicide, with $59-87 \%$ of suicide deaths having either biopolar or unipolar disorder (Rihmer et al., 2002).

Differences in the percentage of incarcerated suicides versus non-incarcerated suicides who experienced depression before death may be due to prison mental health resources available, improper identification procedures used in prisons, or lack of depressive endorsement by incarcerated men. The means by which depression is measured in incarcerated-suicide related deaths could play a large role in whether depression is found to be associated with suicide (e.g., 
symptom endorsement versus diagnoses made prior to or during incarceration). Incarcerated men may have suffered from depressive symptoms prior to suicide, but may not have had a previous or current depressive diagnosis. Alternatively, it could be possible that incarcerated men may not endorse depressive symptoms during incarceration. For example, Messina, Burdon, and Prendergast (2003) and Zlotnick et al. (2008) found that female offenders were more likely to self-report histories of internalizing disorders than male offenders during interview. Research examining depression reporting tendencies is limited, however, as women are less likely to be incarcerated than men, making such research designs involving gender comparisons difficult to implement. Beyond overall lack of endorsement, researchers have also suggested that self-report assessments, especially those that are face valid, may be open to faking bad or faking good presentations by inmates (Boothby \& Durham, 1999; Correia, 2000; Mills \& Kroner, 2006). Studies have found evidence, however, that incarcerated men do endorse depressive symptoms using self-report instruments, even if those assessments have high face validity (Boothby \& Durham, 1999; Mills \& Kroner, 2005). Regardless of the reason why studies have not always found evidence in support of the association between depression and suicide, depression does seem to be a common problem in incarcerated samples and in some studies has been found to be associated with suicidal outcomes.

\section{Incarceration-Specific Suicide Risk Factors}

A variety of incarceration-specific risk factors have also been found to be associated with suicide. Several studies suggest that type of crime is an important factor associated with suicide risk. In fact, many studies have found that a larger percentage of suicide deaths occur in individuals who have committed violent crimes compared to individuals who have been incarcerated for non-violent crimes (Dooley, 1990; DuRand, Burtka, Federman, Haycox, \& 
Smith, 1995; Hayes, 2012; Rabe, 2012). Way et al. (2005) found that $71 \%$ of suicide cases had been incarcerated for a violent crime. Similar findings were obtained in a five year study of New York State prisoner deaths where $56 \%$ of prisoners who committed suicide were incarcerated for violent crimes that involved physical harm to the victim (e.g., homicide, assault, sexual offense) (Novick \& Remmlinger, 1978). Over a nine-year period, 62\% of individuals incarcerated in Maryland state prisons who committed suicide had been convicted of a major crime against a person, whereas only $35 \%$ had a property-related crime (Salive, Smith, \& Brewer, 1989). Salive et al. (1989) calculated that individuals who had committed violent crimes against a person were 3.4 times more likely to die by suicide than individuals who had been convicted of a property crime.

Conflicting evidence has been reported on whether sentence length is associated with suicide and whether suicide conforms to a particular time during the incarceration period. In their study of New York state prisons, Way et al. (2005) found no evidence for an association between longer minimum sentences and suicide whereas in a four-year study of Canadian prison suicides, the majority of suicide cases were serving sentences of two to five years (Laishes, 1997). In an early study on Maryland state prisons, Salive et al. (1989) found that individuals who were serving a life sentence were 4.7 times more likely to die by suicide than those serving non-life sentences. A recent study on suicide risk in European prisons found that both short (less than one year) and long (twenty years or life) imprisonment lengths were predictive of suicide risk (Rabe, 2012) suggesting a possible bimodal distribution of risk.

Beyond the association between sentence length and suicide risk, several early studies also suggested that inmates were more likely to commit suicide during the early period of their sentence (Marcus \& Alcabes, 1993; Novick \& Remmlinger, 1978; Salive et al., 1989). After 
reviewing the conflicting information on the relation between sentence length and suicide, Frottier and colleagues (2002) conducted a study that investigated all suicides in 29 Australian jails and prisons over a 20 year period, performing statistical analyses to control for risk in relation to time. The authors found evidence for three different periods of high suicide risk: immediately after admission for those on remand as well as two months after admission for those on remand, and an increasing risk for sentenced prisoners throughout custody time. These findings, obtained with a more appropriate statistical technique that takes into account risk in relation to time, suggest that long-term prisoners' probability of committing suicide is higher than that of short-term prisoners, regardless of how much time the inmate has already served in custody.

In general, studies have also found evidence for increased suicide rates in higher security institutions compared to lower security institutions. Salive et al. (1989) found that suicides in the Maryland state prison system were five times more likely to occur in maximum security institutions compared to medium and minimum security prisons. Similarly, in a study examining 1,082 state prisons in the United States, Dye (2010) found that suicides were significantly more likely to happen in maximum or supermaximum prisons than minimum security prisons. Inmates in maximum security prisons were over three times more likely to die by suicide compared to inmates in minimum security prisons, and that rate increased to a little over six and a half times more likely when comparing supermaximum and minimum security prisons. It is important to note that increased rates of suicide in higher custody institutions may be due to the association between type of crime and custody placement in addition to custody level factors (e.g., housing arrangement, visitation procedures, employment opportunities). 
In summary, suicide is a common leading cause of preventable death in incarcerated populations. Research on risk factors associated with suicidal behaviors in incarcerated populations mirrors similar risk factors found for non-incarcerated populations including prior suicidal behavior, substance abuse, and affective disorders. Additionally, inmates who have committed violent crimes, have longer sentences, and are incarcerated in higher custody level institutions are at greatest risk for suicide. The interpersonal theory of suicide will be reviewed next to serve as a theoretical framework that may be particularly helpful in explaining prison suicides.

\section{The Interpersonal Theory of Suicide}

The conceptual premise of Joiner's interpersonal theory of suicide posits that in order for an individual to die by suicide, that individual must have both the desire to die by suicide and have the capability to die by suicide (Joiner, 2005). Although previous theories of suicidal behavior have helped explain what factors may be associated with suicidal behaviors, few theories have distinguished between those who may wish to die by suicide and those who can die by suicide (Ribeiro \& Joiner, 2009). Since its inception, several empirical studies have supported the factors that constitute the interpersonal theory. This section will first review the key components of Joiner's theory. Following this review, empirical evidence in support of the theory's three components will be presented. The following section will then provide both empirical evidence and a conceptual rationale for the theory's main components as applied to an incarcerated population.

According to Joiner, thwarted belongingness and perceived burdensomeness constitute the two factors that are associated with the desire to die by suicide (Joiner, 2005). Baumeister (1991) has found evidence for the important contribution social connectedness plays in 
psychological well-being. When an individual feels as though he or she is disconnected in some way from his or her social network, the feeling as though he or she is no longer part of that network increases the risk for suicidal ideation (Van Orden et al., 2010). Similarly, if an individual perceives that he or she has become a burden within his or her social network, he or she may feel as though his or her existence outweighs the cost of life (Van Orden et al., 2010). Interestingly, both of these factors can be characterized as erroneous; the belief that one is disconnected or is a burden on others may not actually reflect objective reality, but is perceived by the suicidal individual as his or her subjective reality. Although both thwarted belongingness and perceived burdensomeness are associated with increased risk for desire to die by suicide, the experience of both factors simultaneously produces the greatest risk (Van Orden et al., 2010; Van Orden, Witte, Gordon, Bender, \& Joiner, 2008).

The final component of the interpersonal theory pertains to an individual's ability to die by suicide. According to Joiner (2005), humans are guided by an intrinsic instinctual drive for self-preservation. An individual must undergo a difficult task, then, to overcome this drive and thus must acquire the ability to do so. The interpersonal theory states that the ability to engage in lethal self-injury is an acquired ability, one that is learned through repeated exposure and habituation to painful and provocative experiences (Van Orden et al., 2010).

Joiner's concept of acquired capability for suicide was based upon Solomon's opponent process theory (Solomon, 1980; Solomon \& Crobit, 1974). Solomon's theory, which is wellsupported by empirical evidence (Franklin et al., 2010; Gordon et al., 2010; Leknes, Brooks, Wiech, \& Tracey, 2008), suggests that when a stimulus/reinforcer is presented, three major affective phenomena are subsequently observed. These three affective phenomena involve affective/hedonic contrast, affective/hedonic habituation (tolerance), and affective/hedonic 
withdrawal (abstinence). When an organism is exposed to a stimulus/reinforcer, an affective response (A) will emerge. Once this stimulus/reinforcer is removed, an opposing affective hedonic response will then emerge (B). Over time, with repeated exposure to the stimulus/reinforcer, the A state becomes weaker and the B state becomes stronger and longer lasting. In other words, the original response to the stimulus/reinforcer will weaken and the opposing response (which is affectively qualitatively different) will strengthen. According to Solomon, and research supporting his theory, the dynamic hedonic response pattern occurs whether the A state is pleasurable or aversive. Furthermore, the opponent process is strengthened through use and weakened through disuse.

The extension of Solomon's opponent process theory to suicidal behavior helps to explain how an acquired capability for suicide may emerge due to repeated exposure to painful and provocative events over time. An individual who is repeatedly exposed to painful and provocative experiences will eventually become habituated to these experiences based upon the activation of the opponent loop, and will consequently develop greater pain tolerance and increased fearlessness. For example, during the first free-fall when parachuting, almost all individuals display some type of a fearful reaction (Solomon, 1980). Following this initial reaction, affective habituation emerges and fearful reactions become extinct. In its place, a withdrawal reaction emerges, characterized by an opposing hedonic tone; this reaction often consists of behaviors consistent with exhilaration. With repeated exposure to the original fearinducing stimulus, the initial response (fear) is suppressed, while the hedonically opposite response (exhilaration) strengthens. Initially aversive painful and provocative events eventually become positive reinforcers due to the opponent process mechanism. With repeated exposure, then, the original self-preservation instinct (typically involving some aspect of fear or pain), is 
overcome by a new response that contributes to greater acquired capability to enact lethal selfharm.

Based on this reasoning, Joiner (2005) argues that the most direct pathway to acquired ability to enact lethal self-harm is through previous suicide attempts, which is consistent with data that suggest prior suicide attempts are the strongest predictor of future suicide (Brown et al., 2000) even after controlling for established suicide risk factors like hopelessness and depression (Joiner et al., 2005). Additionally, literature supports the claim that repeated exposure to selfinjurious events can also increase acquired capability for suicide. For example, Nock, Joiner, Gordon, Lloyd-Richardson, and Prinstein (2006) found that adolescents who engaged in multiple methods and longer periods of non-suicidal self-injury were found to have the highest rates of past suicide attempts. Furthermore, individuals who had the longest history of non-suicidal self injury and who reported the least pain during non-suicidal self injury episodes were almost two times more likely than others to have attempted suicide in the past. Other studies have also reported differences in pain tolerance and pain processing in individuals who have attempted suicide compared with those who had never attempted (Orbach, et al., 1996; Orbach, Mikulincer, King, Cohen, \& Stein, 1997). Similarly, veterans who have been severely injured showed higher threshold and tolerance for thermal pain when compared to veterans who were lightly injured (Dar, Ariely, \& Frenk, 1995).

The three conceptual pieces of Joiner's interpersonal-theory have been tested in undergraduate, clinic outpatient, and military samples. Results have consistently found support for the interpersonal theory even across samples. These empirical studies will be reviewed next, organized by type of sample and component. 
Thwarted belongingness, perceived burdensomeness and acquired capability for suicide have been measured in undergraduate samples. In a study of 309 undergraduates, Van Orden, et al. (2008) found that thwarted belongingness and perceived burdensomeness were significantly correlated with suicidal ideation. Using a hierarchical multiple regression, the authors found that in the sample of undergraduates, after controlling for age, gender, and depressive symptoms, perceived burdensomeness and thwarted belongingness predicted suicidal ideation, accounting for an additional $9 \%$ of the variance in current suicidal ideation. Only perceived burdensomeness significantly predicted suicidal symptoms whereas thwarted belongingness did not. In the last step of the hierarchical regression, the interaction between perceived burdensomeness and thwarted belongingness significantly predicted suicidal ideation and accounted for an additional $4 \%$ of the variance. Follow-up analyses of the interaction suggested that the combined presence of high levels of thwarted belongingness and high levels of perceived burdensomeness were associated with the highest levels of suicidal ideation.

In addition to finding support for the relations among thwarted belongingness, perceived burdensomeness, and suicidal ideation, a study by Bender, Gordon, Bresin and Joiner (2011) also found support for the association between painful and provocative events and acquired capability for suicide amongst undergraduates. In a sample of 182 undergraduate students, Bender and colleagues (2011) collected information on undergraduates' impulsivity, pain tolerance, and acquired capability levels as well as history of painful and provocative events. Impulsivity was measured with the Barratt Impulsivity Scale (BIS; Patton, Stanford, \& Baratt, 1995) and pain tolerance was assessed with a pressure algometer protocol. Additionally, acquired capability for suicide was measured with the Acquired Capability for Suicide (ACSS; Van Orden et al., 2008) scale. The authors found a positive association between pain tolerance and acquired capability 
for suicide, confirming the conceptual premise of acquired capability for suicide. Additionally, results supported a mediation model such that painful and provocative events mediated the relation between impulsivity and acquired capability for suicide and between impulsivity and pain tolerance. These results suggest that impulsivity alone does not directly influence acquired capability for suicide, but rather, impulsivity is related to acquired capability due to the accumulative exposure to painful and provocative events.

Similar findings to those gathered with undergraduate samples have also been obtained in clinical outpatient samples. To build upon the findings from the undergraduate sample, Bender et al. (2011) also tested whether painful and provocative events mediated the relation between impulsivity and acquired capability for suicide in an outpatient sample. The authors tested the mediation model in 516 outpatient community mental health patients, and again measured levels of impulsivity and acquired capability levels (with a shortened version of the ACSS), along with assessing exposure to painful and provocative life events. A different measure of impulsivity, the urgency, premeditation, perseverance, and sensation seeking impulsive behavior scale (UPPS; Whiteside \& Lynam, 2001), was used to purposefully determine whether previous results would replicate with a different measure of impulsivity. Again, results supported a mediation model such that painful and provocative events mediated the relation between impulsivity and acquired capability for suicide.

Van Orden et al. (2008) have also found support for the association between painful and provocative events and acquired capability for suicide. First, the authors demonstrated that past suicide attempts significantly predicted acquired capability scores (as measured with the ACSS) in a sample of 228 clinical outpatients. As expected, gender was related to acquired capability for suicide, such that men were more likely to endorse higher levels of acquired capability for 
suicide. Next, in a hierarchical regression analysis, after controlling for demographics, suicidal ideation, and depressive symptoms, painful and provocative events were found to explain an additional $7 \%$ of the variance in acquired capability scores.

To determine what type of individuals are at greatest risk of suicide, Van Orden et al. (2008) tested whether the interaction of perceived burdensomeness and acquired capability for suicide would significantly predict clinician ratings of suicide risk. In a sample of 153 clinical outpatients, after controlling for age, gender, and depressive symptoms, acquired capability and perceived burdensomeness significantly predicted clinician-rated risk for suicide. Next, the interaction between perceived burdensomeness and acquired capability for suicide was found to significantly predict suicide risk, such that acquired capability predicted elevated risk for suicide only at high levels of perceived burdensomeness. Although this study did not measure the final component of the interpersonal theory (thwarted belongingness), the study's findings support the premise that both suicide desire and acquired capability for suicide are necessary, but not sufficient by themselves, to result in suicidal behavior.

The relation between acquired capability for suicide and life events has also been tested among groups of depressed individuals. Smith, Cukrowicz, Poindexter, Hobson, and Cohen (2010) predicted that depressed individuals who had previously attempted suicide would report greater levels of acquired capability for suicide and painful and provocative life events compared to depressed suicide ideators and controls. Significant group differences were found in a multivariate analysis of covariance in the prediction of acquired capability, painful and provocative events, and life experiences. Follow-up analyses indicated significant effects for the acquired capability and painful and provocative events but not for general life experiences. Hypotheses were partially supported in that suicide attempters reported higher scores on the 
acquired capability for suicide than ideators and higher scores on the painful and provocative events than both ideators and controls. The authors suggest that controls and attempters may not have differed on acquired capability for suicide scores due to the fact that acquired capability for suicide can be established through a variety of means (e.g., bungee jumping) and is a separate entity from desire for death. Notably, this study also provided support for the notion that painful and provocative events, and not just general negative life events, are relevant in the development of acquired capability for suicide.

The components of the interpersonal theory have also been tested in military and combat experienced samples. In a preliminary test of the theory's components in a military sample, Bryan, Morrow, Anestis and Joiner (2010) compared 88 junior enlisted active duty Airmen to non-military samples previously discussed from the Van Orden et al. (2008) studies. The military sample was found to report lower levels of perceived burdensomeness compared to the undergraduate sample but did not differ in thwarted belongingness. In contrast, the military sample was found to have higher levels of acquired capability for suicide than the non-military outpatient sample. Importantly, the military sample had a significantly higher acquired capability for suicide than a non-military subgroup of multiple suicide attempters. In a hierarchical regression, suicidal history was predicted only by acquired capability, and a two way interaction between perceived burdensomeness and acquired capability significantly predicted suicidal history. As previously demonstrated, the relation between perceived burdensomeness and acquired capability in the prediction of suicidal history was only significant at mean levels and higher of acquired capability.

Bryan, Cukrowicz, West, and Morrow (2010) also tested theory components in a sample of 522 service members who were deployed in support of Operation Iraqi Freedom. Again, mean 
acquired capability scores were significantly higher than Van Orden and colleague's (2008) civilian populations. More combat experience was associated with higher levels of all three theory components, though combat exposure did not uniquely explain variance in perceived burdensomeness and thwarted belongingness, after controlling for the presence of other variables (i.e., demographics, past suicidality, PTSD, and depression). In contrast, even after controlling for the above factors, higher scores on combat exposure were significantly associated with greater levels of acquired capability for suicide. The authors note, however, that combat experience only explained a small portion of the total variance in acquired capability $(4.24 \%$ unique variance due to combat). The lack of a relation between combat exposure and thwarted belongingness/perceived burdensomeness support the fact that combat exposure would not be associated with desire for suicide, but instead would affect acquired capability levels.

\section{The Interpersonal Theory of Suicide Applied to Incarcerated Individuals}

Although no research has tested the components of Joiner's interpersonal theory of suicide in an incarcerated population, there is both a conceptual and empirical basis for such research. A brief outline of the conceptual rationale for the applicability of Joiner's model in incarcerated individuals will be provided. Then, empirical support for factors associated with theory components will be addressed. Finally, results from a preliminary study of perceived burdensomeness, thwarted belongingness, and acquired capability for suicide in an incarcerated population will be briefly reviewed.

Conceptually, both individual factors as well as contextual factors could contribute to the desire to die by suicide in addition to the capability to die by suicide in incarcerated individuals. As previously described, incarcerated individuals endorse feelings of loneliness and isolation and commonly experience relationship histories characterized by conflict and abuse (Suto \& Arnaut, 
2010). These factors have been associated with suicidal ideation and are associated with loneliness and absence of reciprocal care, the two dimensions subsumed within thwarted belongingness (Van Orden et al., 2010). For example, suicides often occur in higher security institutions where inmates are often housed in isolation or have limited access to resources, which may also impact perceptions of belongingness. DeWall and Baumeister (2006) have also found evidence that emotional and physical painful experiences, including social exclusion in particular, may influence both the desire to die by suicide as well as the capability to die by suicide. Furthermore, incarcerated individuals may experience factors related to liability and self-hate, the two dimensions of perceived burdensomeness (Van Orden et al., 2010). Distress from incarceration, including low-self esteem and guilt, may increase the inmate's belief that he is a burden on family or society more generally (Van Orden et al., 2010). Alternatively, it could be possible that individuals with high levels of psychopathy may experience less perceived burdensomeness and thwarted belongingness due to the experience of emotional detachment (e.g., immunity to guilt and shame, shallow emotions; Cleckley, 1976; Patrick, Bradley, \& Lang, 1993).

Literature suggests that inmates, especially those who are suicidal, often report feeling lonely and isolated. In a study examining the relation between loneliness and self-harm in a South Australian remand facility, Brown and Day (2008) found that prisoners who scored higher on loneliness reported higher levels of suicide related factors, including suicidal ideation, depression, and hopelessness. Those who reported greater loneliness often perceived lower levels of social support than those who reported fewer symptoms of loneliness. The prisoner's perception of social support may be an essential factor associated with suicidal behaviors such that those who are isolated from family members and outside contacts and who make few friends 
in prison may be more likely to desire suicide (Brown and Day, 2008). Inmates may feel lonely due to disconnection from the outside world and may continue to feel isolated even despite communicating with other inmates and family members (Suto \& Arnaut, 2010). Relationships between inmates in prison may be limited (Liebling \& Arnold, 2012) and if an inmate is unable to get along or fit in with other inmates this may further compound the feeling of thwarted belongingness (Suto \& Arnaut, 2010). Almost half of inmates who died by suicide in Canada over a four year period reported feeling isolated or had negative relationships with staff and peers (Laishes, 1997). A study of interpersonal rejection among prison inmates found that incarcerated men who reported high levels of depressed negative affect were more likely to be rejected by other inmates, corroborating the potential relation between loneliness, social support, and depression (Marcus, Hamlin, \& Lyons, 2001).

Beyond loneliness, other studies found evidence suggesting that inmates may perceive lack of social support during incarceration. The number of visits and letters received per month was found to be associated with lower levels of anxiety in one study (Cooper \& Berwick, 2001) and lack of visits by significant others was associated with suicidal behavior in another (Fruehwald, Frottier, Matschnig, \& Eher, 2003). Inmates who reported experiencing lifetime, one year, and one week suicidal ideation reported having small primary support groups and lack of social support (Jenkins et al., 2005). In their study of the impact of incarceration on intimate relationships, Harman, Smith, and Egan (2007) found that incarcerated men reported social and emotional withdrawal from partners as a primary coping strategy. Literature suggests that the impact of incarceration on thwarted belongingness may be reduced when institutions adopt mechanisms to support relationships between inmates and family members. For example, men who were able to receive conjugal visits (involving overnight family visits in a private setting on 
facility grounds) through a family reunion program endorsed feeling closer to their wives than men who were not part of the program (Carlson \& Cervera, 1991).

As previously reported, incarcerated individuals are less likely to be married (Blaauw et al., 2005; Charles et al., 2003). If an inmate is married or has a partner he left behind, the breakdown in communication that may occur due to incarceration may affect perceptions of burdensomeness. Many incarcerated individuals feel the pressure to try and support family members, both through monetary and emotional means, but may have difficulty doing so. Studies suggest that guilt may be a common emotion experienced by incarcerated individuals (Harman et al., 2007), especially those who die by suicide (Daniel \& Fleming, 2005), due to role strain incarceration placed upon family members. Loss of economic assistance to the family, in addition to burdening family members to help with one's own economic status, may increase these role strains and feelings of guilt in the incarcerated individual.

Similar to studies of acquired capability for suicide in military and combat experienced samples, incarcerated individuals, due to their history of behaviors, may also have increased levels of acquired capability for suicide. Engaging in a history of crime-related behaviors, often associated with dangerous activities (e.g., shootings, fights), in addition to having prior suicide attempts, should directly influence an individual's capability of suicide, potentially lowering one's fear of death. Relatedly, drug use and abuse (e.g., use of needles) may also directly increase acquired capability for suicide by altering physical pain tolerance. A study of pain tolerance found that incarcerated men had higher tolerance for pain than controls during an experimental task that used electrodes on participants' forearms, supporting the hypothesis that incarcerated individuals may have altered pain tolerance levels (Fedora \& Reddon, 1993). Higher testosterone levels have been found in men who have committed violent crimes compared with 
men who committed non-violent crimes (Dabbs, Carr, Frady, \& Riad, 1995), an important finding given that males with higher levels of testosterone are more likely to engage in risky behaviors (Fink, Neave, Laugton, \& Manning, 2006). The association between testosterone and aggression, however, is not conclusive; the relation may be explained by other environmental or learning experiences (Zitzmann \& Nieschlag, 2001) or via interaction effects between biology (e.g., testosterone and serotonin interaction; Birger et al., 2003) and environment. Regardless, hormonal changes involved in aggressive or impulsive behaviors may be yet another factor associated with incarcerated individuals and the risk for higher acquired capability for suicide.

A variety of mechanisms may serve as ways to increase acquired capability for suicide in inmates. For example, inmates have been found to experience a large number of traumatic life events like sexual abuse, physical maltreatment, emotional maltreatment, and suicide attempts by other family members (Blaauw, Arensman, Kraaij, Winkel, Bout, 2002; Sarchiapone et al., 2009). Inmates with substance abuse problems, a pathway to acquired capability to enact lethal selfinjury in and of itself, are more likely than inmates without substance abuse problems to have a greater history of prior incarcerations, exhibit more violent behaviors during detention, have a history of multiple suicide attempts, histories of childhood trauma, and greater levels of impulsivity (Cuomo, Sarchiapone, Di Giannantonio, Mancini, \& Roy, 2008).

Antisocial personality disorder, marked by impulsive and dangerous behaviors, is a common diagnosis in incarcerated populations and it has been associated with suicidal behaviors (Verona, Patrick, \& Joiner, 2001). In their study of male prison inmates, Verona and colleagues (2001) suggest that impulsive and aggressive antisocial deviance may be a dispositional vulnerability in incarcerated antisocial populations. It could be, however, that impulsivity and its 
relation to suicidal behaviors may be mediated by painful and provocative events that increase acquired capability for suicide.

Both a conceptual and empirical rationale supports the use of Joiner's interpersonal theory in studying suicidal behaviors in incarcerated populations. Incarcerated individuals, through a variety of experiences both before and during incarceration, may be at increased risk for developing feelings of perceived burdensomeness and thwarted belongingness and may have higher levels of acquired capability for suicide. Although research has found support for the interpersonal theory in other populations, no published studies have examined theory components in an incarcerated population.

A recent preliminary study in an inmate sample using the three components of the interpersonal theory supported the conceptual and empirical rationale for use of the interpersonal model in an incarcerated population (Nazem, Gregg, Baker, \& Fiske, 2012). A total of 136 male inmates from the Federal Correctional Institution (FCI) - Morgantown completed questionnaires assessing components of the interpersonal theory of suicide and suicidal behaviors during routine clinical testing for placement into a residential drug treatment program (note: participants in this preliminary study are different from participants who participated in the main study). For the sample, the mean perceived burdensomeness total was 9.37 (4.62), the mean thwarted belongingness total was 22.46 (11.11), and the mean acquired capability score, using the fiveitem version, was 9.74 (4.31). The mean suicidal behaviors score was 4.00 (2.02). Perceived burdensomeness and thwarted belongingness were significantly correlated with one another $(r$ $=.59, p<.001)$, as were suicidal behaviors and acquired capability $(r=.24, p<.01)$. As expected, perceived burdensomeness and thwarted belongingness were not significantly correlated with 
acquired capability ( $r=-.01$ and -.02 , respectively) but were significantly correlated with suicidal risk ( $r=.42, p<.001$ and $.26, p<.01$, respectively).

Because of its preliminary nature, the findings from this preliminary study should be interpreted with caution. First, the sample may be unique and not representative of the larger inmate population. Study participants were a select group that had applied for entry into a residential drug treatment program. Eventual acceptance and satisfactory progress through the program results in a reduction of time off sentence length, an important factor to keep in mind, as this characterizes the sample (i.e., all participants have history of drug abuse/dependence) and may influence how an inmate completed assessments (e.g., biased responding, including potential reduction in suicidal behaviors endorsed). Second, without a control group, appropriate comparisons between incarcerated individuals and non-incarcerated individuals are difficult. Third, additional information on depressive symptoms and life experiences would assist in the interpretation of study findings. Despite these limitations, this is the first known study of the interpersonal-theory of suicide in an incarcerated population and provides a strong basis for future research in this area.

\section{Statement of the Problem}

Suicide remains one of the leading causes of death for incarcerated individuals, especially those inmates serving time in jails and state prisons. Previous literature has identified a host of factors that are related to suicidal behaviors in incarcerated individuals. Inmates experience suicide risk factors that are similar to those seen in the general population. For example, previous history of suicide attempt or self-harm, histories of substance abuse/dependence as well as affective disorders have been associated with inmate suicides in addition to demographic variables like gender and marital status. Furthermore, several incarceration-specific factors have 
been found to be associated with increased risk for suicide. These incarceration-specific factors include type of offense, sentence length, and institution type.

Although suicide risk factors have been identified in the literature, there is very little theory-driven research on suicidal behaviors in incarcerated populations. Joiner's interpersonal theory of suicide may be useful in conceptualizing and explaining why incarcerated individuals may be at risk for death by suicide. Despite its potential utility in this sample, no published study has directly tested Joiner's theory, or its components of thwarted belongingness, perceived burdensomeness, and acquired capability for suicide, in an incarcerated population. Research on these components is important as a better understanding of these variables will lead to improved identification and prevention of suicidal behaviors in incarcerated individuals. This study examined Joiner's components in an incarcerated population to determine whether inmates report greater levels of perceived burdensomeness, thwarted belongingness, and acquired capability for suicide than non-incarcerated individuals as a way to improve research on the identification and prevention of suicidal behaviors in incarcerated settings.

\section{Specific Aims}

Specific Aim 1: Compare incarcerated individuals and community controls on factors associated with the desire to die by suicide.

Based on the conceptual rationale of the interpersonal theory of suicide, data from the pilot study of these variables in an incarcerated population, and research (cited above) that suggests inmates often report loneliness, isolation and guilt, the following were hypothesized: Incarcerated individuals will endorse greater levels of thwarted belongingness than nonincarcerated individuals (Hypothesis 1), Incarcerated individuals will endorse higher levels of perceived burdensomeness than non-incarcerated individuals (Hypothesis 2). 
Specific Aim 2: Compare incarcerated individuals and community controls on factors associated with the ability to enact lethal self-injury.

Based on previous literature that has examined the types of life events commonly experienced in individuals who are incarcerated, it was hypothesized that incarcerated individuals would report greater exposure to painful and provocative life events than nonincarcerated individuals (Hypothesis 3). Based on the conceptual rationale of the interpersonal theory of suicide, it was hypothesized that incarcerated individuals would endorse higher levels of acquired capability for suicide than non-incarcerated individuals (Hypothesis 4).

Additional exploratory questions: This study also explored whether certain types of painful and provocative life events were differentially associated with acquired capability for suicide in incarcerated individuals (Exploratory 1). The study also explored the relation between sentence length and suicidal risk to determine whether thwarted belongingness (Exploratory2), perceived burdensomeness (Exploratory 3) and acquired capability for suicide (Exploratory 4) operated as mediators in the relation between sentence length and suicidal risk.

\section{Method}

\section{Participants}

Inmate population. A total of 124 inmates from the Federal Correctional Institution (FCI) - Morgantown completed specified study assessments during clinical intake testing. After data cleaning procedures, the inmate population sample size was 114. Inmate participants were serving an average sentence length of 68.26 (64.72) months (range: 2-360 months). The most common offenses committed by the inmates were drug-related (65.79\%) and white color crimes (23.68\%). Most inmates had no history of prior violent offenses (81.58\%), but many had been incarcerated for another offense prior to the current incarceration (68.42\%). Finally, most 
inmates were not transferring from another facility $(64.04 \%)$. Table 1 provides further demographic information on the inmate population.

Control population. A total of 117 men from the community were recruited and provided informed consent for study participation. Participants were recruited from a variety of community events including athletic events (e.g., University sporting events, child softball leagues) and community exhibits (e.g., pet show) as well as other general community locations (e.g., gyms, cafeterias). During recruitment, a five-year age band recruitment strategy was used as a way to match control participant ages with inmate ages. Two individuals were unable to complete all of the study questionnaires; demographic information for these individuals was missing.

Additionally, a total of 16 community control participants (13.68\%) indicated that they had been previously incarcerated in a jail or prison. Per study protocol, these individuals were ineligible to serve as community controls for subsequent analyses, however, information on these individuals is provided for descriptive comparisons. These individuals are identified as "previously-incarcerated controls."

After data cleaning procedures, the community control sample size was 96 and the previously-incarcerated control sample size was 15 . Table 1 provides further demographic information on the community control and previously-incarcerated control populations.

\section{Procedures}

Inmate population. Data for inmates at FCI Morgantown were obtained from measures completed during routine intake assessments for the facility. Inmates completed intake assessments typically within one week of transfer/placement in the facility. All data were deidentified before being provided to the investigator for use as secondary-data analysis. Because 
inmates had completed study assessments for clinical purposes, they were not provided with compensation.

Control population. Potential community control participants were approached at a variety of in-person data collection locations (e.g., community events, children's sporting events, campus athletic events). After a potential community control participant was approached, he was asked to provide informed consent and was given study questionnaires for completion. All participants were provided with a list of mental health resources and a $\$ 5$ gift card immediately following informed consent.

\section{Measures}

Acquired capability. The Acquired Capability for Suicide Scale (ACSS; Bender et al., 2011; Appendix A) was used to assess levels of acquired capability for lethal self-injury. The ACSS is a 20-item self-report measure designed to assess one's fearlessness and habituation to painful stimuli, including self-injury. Response options range from zero to four, with seven reverse items included. Higher scores on the ACSS are indicative of greater acquired capability for suicide. The ACSS has good internal consistency when used with undergraduate students ( $\alpha$ $=.83)$ and with outpatient participants $(\alpha=.90$; Bender, et al., 2011). Additionally, the scale has demonstrated concurrent validity with measures of suicidal ideation and discriminant validity with measures of depression (Van Orden et al., 2008). The inter-item consistency in the current study was adequate $(\alpha=.77)$.

Life events. Two scales were included to assess the extent to which individuals would report experiencing dangerous, impulsive, or painful events throughout life. These life events were measured with the Impulsive Behaviors Scale (IBS; Rossotto, Yager, \& Rorty, 1994; Appendix B) and the Painful and Provocative Events Scale (PPES; Bender et al., 2011; 
Appendix C). Previous research has combined the PPES and the IBS into one composite measure (Van Orden et al., 2008). When completing this measure, participants indicate how many times they have experienced each life event (e.g., skydiving, victim of abuse, physical fights) by endorsing one of the following response options: never, once, on occasion, sometimes, and regularly. The PPES/IBS has good internal consistency when used with undergraduate students using a 43-item measure (IBS: 25 items, PPES: 18 items; $\alpha=.89$; Bender et al., 2011) and in three samples of adult outpatients using both a 35-item shortened measure (IBS: 25 items, PPES: 10 items) and a 49-item measure (IBS: 25-items, PPES: 24 items; $\alpha=.89$-.90; Bender et al., 2011; Smith et al., 2010; Van Orden et al., 2008). The inter-item consistency of the 49-item measure in the current study was adequate $(\alpha=.89)$.

Interpersonal needs. To assess levels of thwarted belongingness and perceived burdensomeness, the Interpersonal Needs Questionnaire (INQ; Van Orden et al., 2008; Van Orden, Cukrowicz, Witte, \& Joiner, 2012) was administered (See Appendix D). The current study used the newly revised 15-item INQ (Van Orden et al., 2012). The INQ consists of nine items that measure thwarted belongingness and six items that measure perceived burdensomeness. Response options range from "not at all true" to "very true for me," on a 7 point Likert scale. Higher scores are indicative of greater levels of thwarted belongingness and perceived burdensomeness. Internal consistency has been adequate for both the belongingness items (using a five-item scale; $\alpha=.85$ ) and the perceived burdensomeness items (using a sevenitem scale, $\alpha=.89$ ) in undergraduate students. Both thwarted belongingness and perceived burdensomeness have demonstrated convergent associations with related interpersonal constructs including loneliness, social support, self worth, and death ideation, whereas divergent associations have been demonstrated with measures of depression and posttraumatic stress 
(Bryan, Cukrowicz et al., 2010; Van Orden et al., 2008; Van Orden et al., 2012). The inter-item consistency of the 6-item perceived burdensomeness scale $(\alpha=.84)$ and the 9-item thwarted belongingness scale $(\alpha=.88)$ in the current study were adequate.

Suicidal risk. Suicidal risk was assessed with the Suicidal Behaviors Questionnaire Revised (SBQ-R; Osman et al., 2001; Appendix E). The SBQ-R, revised from the Suicidal Behaviors Questionnaire (Linehan, 1981), consist of 4-items that assess past and future suicidal behaviors; total score on the SBQ-R ranges from 3-18. Scores above seven for the general population and above eight for clinical samples have been used as an indicator of clinically significant suicidal ideation (Osman et al., 2001). Moderate reliability has been demonstrated in non-clinical $(\alpha=.85)$ and clinical $(\alpha=.88)$ samples and the measure has been found to differentiate between suicidal and non-suicidal subgroups in clinical and nonclinical samples (Osman et al., 2001). The inter-item consistency of the SBQ-R in the current study was adequate $(\alpha=.81)$

Depression. The Center for Epidemiological Studies Depression Scale (CESD; Radloff, 1977; Appendix F) was used as a measure of the frequency of depressive symptoms. The CESD is a 20 -item measure where participants indicate how often they have experienced each symptom of depression over the past week with response options ranging from 0 (rarely or none of the time) to 3 (all or most of the time). Four reverse-scored items are included in the measure and higher scores are indicative of greater depressive symptom frequency. Internal consistency for the CESD has been found to range from .84 to .90 (Radloff, 1977). The inter-item consistency of the CESD in the current study was adequate $(\alpha=.89)$. 
Demographic questionnaire. A demographic questionnaire was used to collect information on age, race, marital status, and education level for control participants to match the demographic information available in the inmate population (See Appendix G).

\section{Analysis Plan}

Before running analyses, several checks were carried out to maximize data quality. A total of eight inmates were removed from the dataset due to extremely biased responding between reverse and non-reversed items on the INQ measures and/or the ACSS. Another inmate was found to have biased responding on the CESD (i.e., answered all zeros across reverse and non-reversed items) and was removed. Finally, one inmate did not complete the INQ measures and the ACSS correctly. In total, of the 124 inmate participants who completed the clinical assessments, 10 inmates $(8.06 \%)$ were removed from the dataset resulting in a final sample size of 114 inmates.

The same data quality checks were carried out with community controls and previouslyincarcerated controls. A total of three community controls and one previously-incarcerated control were removed from the dataset due to extremely biased responding between reverse and non-reversed items on the INQ measures and the ACSS. As previously mentioned, two community controls terminated early and were therefore not included in data analyses. In total, of the 99 community controls who completed all study assessments, three community controls $(3.0 \%)$ were removed from the dataset resulting in a final sample size of 96 community controls. Of the 16 previously-incarcerated controls, one previously-incarcerated control $(6.3 \%)$ was removed from the dataset resulting in a final sample size of 15 previously-incarcerated controls.

Multiple imputation was used as a method to handle missing data using SAS and the SAS PROC MI procedure for descriptive, correlational, and regression analyses. In total, $4.73 \%$ of all 
data points were missing and were therefore imputed. The data were imputed five times and were then combined to yield the imputed results. $\mathrm{R}^{2}$ and beta values were determined by averaging values across the five imputations (von Hippel, 2009). Prior to the exploratory factor analysis, single imputation was used to handle missing data points on the combined painful and provocative events scale items using the SPSS 19 MVA add on.

Analyses included linear regressions and an exploratory factor analysis. Prior to conducting all analyses, data were checked to ensure conformity to statistical assumptions (e.g., normality, linearity, and multicollinearity). A total of four potential outliers in the community control sample, six potential outliers in the incarcerated sample, and one potential outlier in the previously-incarcerated control sample were identified (z score > 3.3; Tabachnick \& Fidell, 2007). Visual inspection of these cases suggested that the cases were part of the intended sample and when analyses were run with and without these outliers, no differences were found in results. Consequently, these potential outliers were not excluded from the dataset. Both the Suicidal Behaviors Questionnaire $($ skew $=2.83$, kurtosis $=8.44$ ) and the perceived burdensomeness scale $(\mathrm{skew}=2.54$, kurtosis $=6.92)$ deviated from normality. A square-root transformation was employed and following the transformation, both the skew and kurtosis for the Suicidal Behaviors Questionnaire $($ skew $=2.37$, kurtosis $=5.42)$ and the perceived burdensomeness scale $($ skew $=2.00$, kurtosis $=3.94)$ were improved.

A t-test was used to determine whether there were demographic differences on age and education between inmates and community controls. As shown in Table 1, there were no significant age differences between the two groups, however, community controls and inmates significantly differed on education. Pearson's product moment correlations indicated that age and education were significantly associated with several key variables of interest in this study and 
were therefore included as covariates in each subsequent regression. Race significantly differed between inmates and community controls; a majority of the community control sample consisted of White participants (91.67\% of the community control sample was White) whereas the inmate sample consisted of a significantly greater proportion of Black participants (47.37\% of inmate sample was Black).

Descriptive, correlational, and regression analyses were performed using SAS 9.3 statistical software. SPSS 19 statistical software was used for the exploratory factor analyses.

\section{Results}

Descriptive statistics of key study variables by group, as well as the results of t-tests comparing inmates and community controls on these variables, are provided in Table 2. Mean levels of perceived burdensomeness and thwarted belongingness did not differ between inmates and community controls, however, community controls reported higher levels of acquired capability for suicide than inmates. Although inmates reported significantly higher levels of depressive symptoms than community controls, inmates were found to report significantly lower levels of suicidal risk when compared to community controls. These mean level differences on depressive symptoms and suicidal risk were no longer significant when controlling for age and education (results not shown). Generally, suicidal risk was low among all three groups, with most individuals scoring the minimum on the measure (minimum score on the SBQ-R $=3$ ). Endorsement of items on the SBQ-R indicated that few inmates endorsed experiencing suicidal ideation and few reported previous suicide plans or attempts whereas suicidal ideation and previous suicidal behaviors were endorsed more frequently in the community control and previously-incarcerated control samples (see Table 3). 
Correlations among key study variables by group are provided in Table 4, Table 5, and Table 6. As expected, perceived burdensomeness and thwarted belongingness were significantly correlated with each other in all three samples and were unrelated to acquired capability for suicide in the inmate and community control samples. The strength of the relation between perceived burdensomeness and suicidal risk $(Z=2.31, p<.05)$ as well as thwarted belongingness and suicidal risk $(Z=2.15, p<.05)$ was stronger in community controls compared to inmates. There was a significant moderate correlation between depressive symptoms and suicidal risk across all three samples. The strength of the relations between acquired capability for suicide scale score and the painful and provocative event scales were small but significant; the strongest relation was seen between scores on the ACSS and the PPES. In the sample of previously-incarcerated controls, the pattern of correlations differed from those seen in the inmate and community samples; higher scores on acquired capability for suicide scale were significantly associated with lower levels of depressive symptoms, perceived burdensomeness, and thwarted belongingness scores.

To determine whether incarcerated individuals endorsed greater levels of suicidal risk factors (i.e., thwarted belongingness, perceived burdensomeness, acquired capability for suicide, painful and provocative life events) compared to community controls, several linear regressions were used. In these regressions, group membership (incarcerated or non-incarcerated) was dummy coded as an independent variable. Education and age were included as covariates in these models.

Incarcerated individuals were not found to significantly endorse greater levels of thwarted belongingness compared to community controls, $B=-0.52(S E=1.70), p=\mathrm{ns}, R^{2}=$ 0.04, disconfirming Hypothesis 1. Similarly, incarcerated individuals were not found to 
significantly endorse greater levels of perceived burdensomeness compared to community controls, $B=-0.07(S E=0.10), p=\mathrm{ns}, R^{2}=0.04$, disconfirming Hypothesis 2 .

There were no significant differences between incarcerated individuals and community controls in reported exposure to painful and provocative events, $B=-1.01(S E=2.92), p=\mathrm{ns}, R^{2}$ $=0.03$, disconfirming Hypothesis 3 . Hypothesis 4 was also disconfirmed as community controls reported significantly greater mean levels of acquired capability for suicide than incarcerated individuals, $B=7.22(S E=1.81), p<.001, R^{2}=0.11$.

Due to the disproportionate racial distribution between the two samples, exploratory analyses were conducted to determine whether there were mean level differences within race. In a series of linear regression models, inmates and community controls were found to differ significantly within race in levels of acquired capability, depressive symptoms, and suicidal risk. Specifically, White community controls reported greater levels of acquired capability ( $M=49.3$, $S D=9.6)$ than White inmates $(M=44.2, S D=11.6)$, White inmates reported greater levels of depressive symptoms $(M=15.7, S D=10.4)$ than White community controls $(M=9.5, S D=7.6)$, and Black community controls reported significantly greater levels of suicidal risk ( $M=5.0, S D$ $=1.5)$ than Black inmates $(M=3.2, S D=0.6)$. No other analyses by race were significant, however, the small sample size of Black community controls $(n=4)$ largely affected the power necessary to detect mean level differences between groups within race.

To explore whether certain types of painful and provocative life events were differentially associated with acquired capability for suicide in incarcerated individuals (Exploratory 1), an exploratory factor analysis (EFA) was utilized to determine whether certain painful and provocative events would cluster into meaningful factors. Principal components analysis with varimax rotation was performed on the full 49-item scale of events (combination of 
IBS and PPES). Data met the minimum value of the Kaiser-Meyer-Olkin (KMO) measure of sampling adequacy (minimum $\mathrm{KMO}=.5, \mathrm{KMO}$ value obtained $=.6$ ). Potential univariate outliers were retained in the sample as removal of these cases would have resulted in removal of all variance in some variables (outliers identified were in many cases the only indi viduals who endorsed levels beyond the minimum and were therefore also considered a meaningful part of the sample).

Initial analysis yielded a 16-component solution which accounted for $73.53 \%$ of the total variance. This 16-component solution included several overlapping item loadings and items that did not load onto any individual factor. Analysis of the scree plot suggested other potential component solutions including four-, nine-, 12-, and 14-component options. A parsimonious four-component solution was ultimately used as this model had improved conceptual fit over the remaining options and was the most appropriate point of inflexion upon visual inspection of the scree plot.

The determinant value of the principal component analysis was below the suggested cutoff of .00001, however, visual inspection of the correlation matrix did not find any variables that were correlated above .90 , which would suggest problems with multicollinearity (Field, 2005). The four-component solution accounted for $36.24 \%$ of the total variance. The partition of variance accounted for by each of the four factors can be found in Table 7. Item-loadings are presented in Table 8 . Only loadings over .40 , the a priori defined cut-off, were retained. There were a total of nine items that did not load over .40 on any of the four factors (IBS2, IBS8, IBS9, IBS12, IBS15, PPES3, PPES5, PPES9, and PPES15). Items that loaded onto more than one factor were retained under the factor that provided the best conceptual match with the other items 
under this component. Information on the conceptual meaning of each factor, as well as descriptive statistics and Cronbach's alpha values for each factor, are described in Table 7.

Next, each factor was entered into a linear regression to determine whether each factor significantly predicted acquired capability for lethal self-injury. A total of three of the four factors were found to be significantly associated with acquired capability (Table 9). An overall regression model that included these three factors was found to significantly predict acquired capability, $F(3,110)=6.66, \mathrm{p}<.001, R^{2}=.39$. Only factor two, however, was independently associated with acquired capability, $\mathrm{t}(1,110)=3.48, \mathrm{p}<.01, \mathrm{~B}=.55, \mathrm{SE}=.16$.

To determine whether theory components mediated the relation between sentence length and suicidal risk (Exploratory 3, 4, \& 5) a linear regression was used to test the association between sentence length and suicidal risk. Sentence length, however, was not predictive of total suicide risk, $B=-0.0008(S E=0.0004), p=\mathrm{ns}, R^{2}=0.03$, past suicide attempt, $B=-0.0005(S E$ $=0.0007), p=\mathrm{ns}, R^{2}=0.01$, or future likelihood, $B=-0.0001(S E=0.0001), p=\mathrm{ns}, R^{2}=0.00$. Furthermore, the mean suicidal risk score for inmates who were serving sentences at or below the median sentence length (46 months) was 4.09 (2.02), whereas the mean suicidal risk score for inmates that were serving more than the median sentence length was $3.23(0.80)$. Sentence length was negatively associated with suicidal risk ( $r=-.17, p=\mathrm{ns})$.

\section{Discussion}

The purpose of the current study was to determine whether incarcerated individuals report greater mean levels of suicidal risk factors compared to community controls. In a sample of federal inmates, there were no significant mean level differences in scores on perceived burdensomeness, thwarted belongingness, and painful and provocative events when compared to community controls. There was a significant difference between mean levels of acquired 
capability for suicide scores, however, community controls endorsed greater levels of this suicide risk factor compared to inmates.

Although there were no significant mean level differences between incarcerated individuals and community controls, it does appear that the constructs of thwarted belongingness and perceived burdensomeness are relevant to an inmate population. Inmates were as willing to report these interpersonal factors as community controls, which may be an especially encouraging finding with clinical implications. Inmates may be reluctant to report suicidal ideation in the prison setting but willing to report on feelings of thwarted belongingness and perceived burdensomeness. Because these two factors are associated with suicidal ideation, this information could be especially helpful in understanding whether an inmate is at risk for suicidal ideation or may be experiencing suicidal thoughts. Additionally, if the inmate is willing to disclose these feelings, in addition to depressive symptoms like they also did in this study, they may be open to participating in psychoeducation classes or group therapy aimed at reducing these negative emotional experiences.

The fact that community controls reported significantly higher mean levels of acquired capability for suicide than incarcerated individuals was a surprising finding. No known published research has examined acquired capability for suicide as measured by the ACSS in a community sample, so it is difficult to ascertain how these mean levels would compare to other community samples. It may be possible that the community controls are uncharacteristically high in the suicidal risk factors due to the demographic region from which they were drawn. It could also be possible that inmates were reluctant to disclose information related to acquired capability for suicide (including endorsement of impulsive, painful, and provocative events). Regardless, 
the increased levels of acquired capability for suicide in the community controls is an interesting finding and one that requires further examination in future studies.

There are several factors that may help to explain why incarcerated individuals did not report greater mean levels of acquired capability, suicidal risk, and total events than community controls. As previously discussed, the community control sample may have had higher levels of these variables than we would expect in other community samples thus potentially serving as a biased control population. It may also be possible that inmates completed some of the questionnaires in a biased fashion. Because some inmates were placing into the facility to begin their sentence, they may not have answered all questions honestly due to impression management. For example, a little over $6 \%$ of the inmates reported that they had never been arrested and $14 \%$ reported that they had never engaged in illegal activity. It is possible that there may have been underreporting of actual experience with painful and provocative events, especially those events that involved illegal and suicidal behaviors, leading to unreliable and invalid estimates of acquired capability for suicide.

An exploratory aim of the study was to better understand what types of factors may be more strongly associated with acquired capability for suicide in incarcerated individuals. A four component solution was found in an exploratory factor analysis of impulsive, painful, and provocative events in inmates and three of these four factors were found to significantly predict acquired capability for suicide. When these three significant factors were entered together in a regression analysis predicting acquired capability for suicide, only the factor comprised of items associated with legal painful and provocative events was found to independently predict acquired capability for suicide. This finding may suggest that certain types of painful and provocative events (e.g., shooting a gun, being shot or stabbed) may be predictive of greater acquired 
capability for suicide more so than other more commonly recognized suicidal risk variables (e.g., prior self-harm) in incarcerated individuals. Alternatively, it could also be possible that these potentially-habituating events, in the context of criminal and/or suicidal history, may be additional factors that lead to greater acquired capability above and beyond the expected increase that would be associated with criminal and suicidal histories. It may also be possible that the inmates in this sample were more comfortable disclosing their experience with non-illegal activities for fear of additional consequences perceived to be associated with reporting. Regardless, the findings from the exploratory factor analysis may help guide prevention efforts as mental health professionals could work with inmates to reduce engagement in further habituating events as a way to decrease continued development of acquired capability for selfharm.

A final exploratory aim of the study was to better understand the relation between an incarceration-specific suicide risk factor (i.e., sentence length) and suicide risk by examining whether Joiner's theory components served as mediators in the relation between sentence length and suicide risk. These analyses were not run, however, as sentence length was not found to be a significant predictor of overall suicide risk, past suicide attempt, or future likelihood of suicide.

The finding that sentence length was not associated with suicide risk adds to and extends the conflicting evidence found in previous research on the association between the two factors. There may be several explanations for this. One, the range of sentence lengths, and the average sentence length, in this population may have been too limited to detect differences by time. Similarly, it could be possible that sentence length is more strongly associated with suicide risk in some inmate populations and not others. For example, sentence length may have a weak association with suicide risk in inmates who have committed similar crimes to those seen in this 
population or in inmates who have served prior sentences especially given that the current sample consisted of a majority of inmates who had served prior sentences. Further, our measurement of suicide risk, which also had a limited range of scores, may suggest that inmates were unwilling to disclose information on suicidal behaviors. Specifically, analyses based on prior suicide attempt and future likelihood were restricted as relatively few incarcerated individuals reported a previous suicide plan, previous suicide attempt, or future likelihood of attempt. Inmates may have believed that negative consequences or other aversive contingencies would be associated with disclosure of suicidal thoughts. It could be possible that the responses of inmates would mirror more closely those of the previously-incarcerated control sample responses if no perceived or actual contingencies existed.

There are several limitations to the current study. As previously mentioned, there may be some evidence to suspect potential response bias on some of the study measures like acquired capability for suicide, total events, and suicidal risk. The current study, however, did not include any measures designed to specifically test for this bias as the study was a secondary data analysis of clinical data for the inmate population. It appears as though under-reporting may have been more likely than over reporting (when comparing to the previously-incarcerated control sample) which would likely make the results a more conservative estimate of what true mean levels may be. Nevertheless, some of the reported results were similar to means reported in a preliminary study of a different sample of federally incarcerated individuals (Nazem et al., 2012) and serve as the first study to provide information on these suicidal risk factors with a control comparison. Future studies may wish to include measures not solely reliant on self-report such as behavioral measures of the constructs. 
The exploratory factor analysis carried out in this study should be interpreted with caution. Researchers suggest sample sizes of at least 200, but preferably 300 , to produce stable factor solutions (Field, 2005). Stronger correlation matrices and item loadings would likely be achieved with a much larger sample size and is a suggestion for future research. Despite being underpowered, the results of the EFA provide a good first estimate as to whether certain painful and provocative events may be more predictive of acquired capability for suicide in incarcerated individuals.

The results of this study may only generalize to similar populations. The incarcerated sample came from a Federal minimum security institution where a majority of the crimes are drug or white collar crime related. Furthermore, inmates in this institution are housed together, which may play a role in the interpersonal variable of belongingness. Previous literature suggests that individuals who are incarcerated for violent crimes and who are serving time in higher security institutions, where they are much more likely to be housed individually, may be more at risk for suicidal behavior. Due to this reason, results from the current study may only generalize to other inmates who have committed similar crimes and are serving time in lower security institutions. The results of this study provide interesting information, however, showing that inmates who came from an institution in which they are housed together still report relatively high levels of thwarted belongingness.

Continued research on specific suicidal risk factors in incarcerated populations, which is guided by theory, is recommended. A longitudinal study capturing levels of perceived burdensomeness, thwarted belongingness, and acquired capability over the entire sentence length would be especially helpful in understanding inmate suicidal risk. A better understanding as to 
how these factors fluctuate with more prison-related experiences and time served, would be beneficial in risk identification and prevention planning.

Replicating the current research in other samples of incarcerated individuals may also be helpful. For example, a study designed to compare levels of the suicidal risk factors among incarcerated individuals at various security levels and with different criminal backgrounds would assist in a better understanding as to why and how some incarcerated individuals are at greater risk for suicide than others. Additionally, studying Joiner's interpersonal theory factors in inmates who have previously reported suicide attempts and in those who report current elevated levels of suicide ideation and/or have engaged in a current attempt would be beneficial in understanding how the theory components are experienced in those with more serious suicidal risk. Results from this study suggest that one factor in the feasibility of this type of research would be to create an environment in which inmates may feel safe that no negative contingencies would result from reporting suicidal behaviors. Results also suggest that the measurement of legal painful and provocative events may be used as a way to estimate acquired capability for suicide and suicide risk as inmates in the current study did in fact disclose these experiences. Finally, conducting similar research in previously-incarcerated populations could also provide contextual information on how the prior experience of incarceration may influence interpersonal theory components.

Additional research examining the association between painful and provocative events and acquired capability for suicide is also warranted. Studies investigating whether certain types of painful and provocative events are differentially associated with acquired capability for suicide would assist in refining Joiner's theory and would provide helpful information on how to appropriately tailor interventions aimed at helping individuals to not engage in further events that 
would lead to even greater levels of acquired capability for suicide. Furthermore, research comparing how these events may be differentially related to acquired capability for suicide between different samples (e.g., incarcerated, veteran, community) may be an especially promising way to better understand why some groups are at higher risk for suicide than other groups. Future studies may also wish to determine whether impulsive and painful event factors have differential effects on acquired capability for suicide or whether a general cumulative effect is more strongly associated with greater levels of acquired capability for suicide.

Finally, there is a current paucity of research on Joiner's theory components measured in community controls. Prior research has mostly focused on measuring component variables in undergraduate, military, outpatient, and older adult samples. A better understanding of the theory components in a non-selected sample could help researchers and clinicians better understand the risk associated with each variable within select populations. This type of research would also help with the identification of correlates associated with each theory component and suicide risk.

Literature suggests that incarcerated individuals, either due to factors that are present prior to incarceration or due to factors encountered during incarceration, are at increased risk for suicidal behaviors. Although previous research has established a variety of factors that may be associated with suicidal behaviors in this population, there has been little theory-driven research in this domain. This study is the only known study to apply Joiner's interpersonal theory of suicide to an incarcerated population. The current study found that incarcerated individuals did not report greater mean levels of suicidal risk factors compared to community controls, however, incarcerated individuals did still endorse mean levels of theory components that are similar to a matched community sample, Future research may benefit from continued use of the interpersonal theory in this population as a way to ascertain why and how incarcerated individuals may be at 
risk for suicidal behaviors. This research could help reduce the number of suicidal behaviors seen in this population both during and after release from prison. 


\section{References}

American Association of Suicidiology (2007). Suicide in the U.S.A. based on current (2007) statistics. Retrieved from American Association of Suicidology website: http://www.suicidology.org

Baumeister, R. F. (1991). Meanings of life. New York: Guilford Press.

Bender, T. W., Gordon, K. H., Bresin, K., \& Joiner, T. E. (2011). Impulsivity and suicidality: The mediating role of painful and provocative experiences. Journal of Affective Disorders, 129, 301-307. doi:10.1016/j.jad.10.07.023

Birger, M., Swartz, M., Cohen, D., Alesh, Y., Grishpan, C., \& Kotelr, M. (2003). Aggression: The testosterone-serotonin link. Israel Medical Association Journal, 5, 653-658. Retrieved from http://www.ima.org.il/imaj/ar03sep-12.pdf

Blaauw, E., Arensman, E., Kraaij, V., Winkel, F. W., \& Bout, R. (2002). Traumatic life events and suicide risk among jail inmates: The influences of types of events, time period and significant others. Journal of Traumatic Stress, 15, 9-16. doi:0894-9867/02/0200-0009/1

Blaauw, E., Kerkhof, J. F. M., \& Hayes, L. M. (2005). Demographic, criminal, and psychiatric factors related to inmate suicide. Suicide and Life-Threatening Behavior, 35, 63-75. doi: $10.1521 /$ suli.35.1.63.59268

Boothby, J. L., \& Durham, T. W. (1999). Screening for depression in prisoners using the beck depression inventory. Criminal Justice and Behavior, 26, 107-124. doi:

\subsection{7/0093854899026001006}

Brown, G. K., Beck, A. T., Steer, R. A., \& Grisham, J. R. (2000). Risk factors for suicide in psychiatric outpatients: A 20-year prospective study. Journal of Consulting and Clinical Psychology, 68, 371-377. doi:10.1037//0022-006X.68.3.371 
Brown, S., \& Day, A. (2008). The role of loneliness in prison suicide prevention and management. Journal of Offender Rehabilitation, 47, 433-449. doi:10.108Q/10509670801992459

Bryan, C. J., Cukrowicz, K. C., West, C. L., \& Morrow, C. E. (2010). Combat experience and the acquired capability for suicide. Journal of Clinical Psychology, 66, 1044-1056. doi:10.1002/jclp.20703

Bryan, C. J., Morrow, C. E., Anestis, M. D., \& Joiner, T. E. (2010). A preliminary test of the interpersonal-psychological theory of suicidal behavior in a military sample. Personality and Individual Differences, 48, 347-350. doi:10.1016/j/paid.2009.10.023

Bureau of Prisons (2011). Quick facts about the bureau of prisons. Retrieved from the Bureau of Prisons website: http://www.bop.gov

Carli, V., Jovanovic, N., Podlesek, A., Roy, A., Rihmer, Z., Maggi, S., . . Sarchiapone, M. (2010). The role of impulsivity in self-mutilators, suicide ideators and suicide attempters - A study of 1265 male incarcerated individuals. Journal of Affective Disorders, 123, 116-122. doi:10.1016/j/jad.210.02.119

Carlson, B. E., \& Cervera, N. (1991). Inmates and their families: Conjugal visits, family contact, and family functioning. Criminal Justice and Behavior, 18, 318-331. doi $10.1177 / 0093854891018003005$

Cavanagh, J. T. O., Carson, A. J., Sharpe, M., \& Lawrie, S. M. (2003). Psychological autopsy studies of suicide: A systematic review. Psychological Medicine, 33, 395-405.

Cleckley, H. (1976). The mask of sanity (5th ed.). St. Louis, MO: CV Mosby. 
Charles, D. R., Abram, K. M., McClelland, G. M., \& Teplin, L. A. (2003). Suicidal ideation and behavior among women in jail. Journal of Contemporary Criminal Justice, 19, 65-81. doi: $10.1177 / 1043986202239742$

Cooper, C., \& Berwick, S. (2001). Factors affecting psychological well-being of three groups of suicide-prone prisoners. Current Psychology, 20, 169-182. doi 10.1007/s12144-0011025-0

Correia, K. M. (2000). Suicide assessment in a prison environment: A proposed protocol. Criminal Justice and Behavior, 27, 581-599. doi:10.1177/0093854800027005003

Cuomo, C., Sarchiapone, M., Di Giannantonio, M., Mancini, M., \& Roy, A. (2008). Aggression, impulsivity, personality traits, and childhood trauma of prisoners with substance abuse and addiction. The American Journal of Drug and Alcohol Abuse, 34, 339-345. doi:10.1080/00952990802010884

Dabbs, J. M., Carr, T. S., Frady, R. L., \& Raid, J. K. (1995). Testosterone, crime, and misbehavior among 692 male prison inmates. Personality and Individual Differences, 18, 627-633. doi:0191-8869(94)00177-4

Daniel, A. E., \& Fleming, J. (2005). Serious suicide attempts in a state correctional system and strategies to prevent suicide. The Journal of Psychiatry \& Law, 33, 227-247. Retrieved from http://heinonline.org/

Dar, R., Ariely, D., \& Frenk, H. (1995). The effect of past-injury on pain threshold and tolerance. Pain, 60, 189-193. doi:10.1016/0304-3959(94)00108-Q

DeWall, N., \& Baumeister, R. (2006). Alone but feeling no pain: Effects of social exclusion on physical pain tolerance and pain threshold, affective forecasting, and interpersonal empathy. Journal of Personality and Social Psychology, 91, 1-15. 
DuRand, C. J., Burtka, G. J., Federman, E. J., Haycox, J. A., \& Smith, J. W. (1995). A quarter century of suicide in a major urban jail: Implications for community psychiatry. American Journal of Psychiatry, 152, 1077-1080.

Dooley, E. (1990). Prison suicide in England and Wales, 1972-87. British Journal of Psychiatry, 156, 40-45. doi:10.1192/bjp.156.1.40

Dye, M. H. (2010). Deprivation, importation, and prison suicide: Combined effects of institutional conditions and inmate composition. Journal of Criminal Justice, 38, 796-806. doi:10.1016/j.jcrimjus.2010.05.007

Fazel, S., Benning, R., \& Danesh, J. (2005). Suicides in male prisoners in England and Wales, 1978-2003. The Lancet, 366, 8-14. doi:10.1016/S0140-6736(05)67325-4

Fazel, S., \& Danesh, J. (2002). Serious mental disorder in 23,000 prisoners: A systematic review of 62 surveys. The Lancet, 359, 545-550. Retrieved from http://www.bulger.co.uk

Fazel, S., \& Seewald, K. (2012). Severe mental illness in 33,588 prisoners worldwide: Systematic review and meta-regression analysis. The British Journal of Psychiatry, 200, 364-373. doi:10.1192/bjp.bp.111.096370

Fazel, S., Grann, M., Kling, B., \& Hawton, K. (2011). Prison suicide in 12 countries: An ecological study of 861 suicides during 2003-2007. Social Psychiatry and Psychiatric Epidemiology, 46, 191-195. doi:10.1007/s00127-010-184-4

Fedora, O., \& Reddon, J. R. (1993). Psychopathic and nonpsychopathic inmates differ from normal controls in tolerance levels of electrical stimulation. Journal of Clinical Psychology, 49, 326-331.

Felthous, A. R. (2011). Suicide behind bars: Trends, inconsistencies, and practical implications. Journal of Forensic Sciences, 56, 1541-1555. doi: 10.1111/j.1556-4029.2011.01858.x 
Field, A. (2005). Discovering statistics using SPSS (2 ${ }^{\text {nd }}$ ed.). Thou sand Oaks, CA: Sage Publications Inc.

Fink, B., Neave, N., Laughton, K., \& Manning, J. T. (2006). Second to fourth digit ratio and sensation seeking. Personality and Individual Differences, 41, 1253-1262. doi:10.1016/j.paid.2006.05.002

Franklin, J. C., Hessel, E. T., Aaron, R. V., Arthur, M. S., Heilbron, N., Prinstein, M. J. (2010). The functions of nonsuicidal self-injury: Support for cognitive-affective regulation and opponent processes from a novel psychophysiological paradigm. Journal of Abnormal Psychology, 119, 850-862. doi: 10.1037/a0020896

Frottier, P., Fruhwald, S., Ritter, K., Eher, R., Schwarzler, J., \& Bauer, P. (2002). Jailhou se blues revisited. Social Psychiatry and Psychiatric Epidemiology, 37, 68-73.

Fruehwald, S., Frottier, P., Matschnig, T., \& Eher, R. (2003). The relevance of suicidal behaviour in jail and prison suicides. European Psychiatry, 18, 161-165. doi:10.1016/S0924-9338(03)00064-6

Gordon, K. H., Selby, E. A., Anestis, M. D., Bender, T. W., Witte, T. K., Braithwaite, S., .. . Joiner, T. E. (2010). The reinforcing properties of deliberate self-harm. Archives of Suicide Research, 14, 329-341.

Harman, J. J., Smith, V. E., \& Egan, L. C. (2007). The impact of incarceration on intimate relationships. Criminal Justice and Behavior, 34, 794-815. doi: $10.1177 / 0093854807299543$

Harris, E. C., \& Barraclough, B. (1997). Suicide as an outcome for mental disorders. British Journal of Psychiatry, 170, 205-228. doi: 10.1192/bjp.170.3.205 
Hayes, L. M. (2011). National study of jail suicides: 20 years later. The National Jail Exchange, 1-6. Retrieved from http://NICIC.gov/NationalJailExchange

Hayes, L. M. (2012). National study of jail suicide: 20 years later. Journal of Correctional Health Care, 18, 233-245. doi:10.1177/1078345812445457

He, X. Y., Felthous, A. R., Holzer, C. E., Nathan, P., \& Veasey, S. (2001). Factors in prison suicide: One year study in Texas. Journal of Forensic Science, 46, 896-901.

Jenkins, R., Bhugra, D., Meltzer, H., Singleton, N., Bebbington, P., Brugha, T., . . Paton, J. (2005). Psychiatric and social aspects of suicidal behaviour in prisons. Psychological Medicine, 35, 257-269. doi:10.117/S0033291704002958

Joiner, T. E. (2005). Why people die by suicide. Cambridge, MA: Harvard University Press.

Joiner. T. E., Conwell, Y., Fitzpatrick, K. K., Witte, T. K., Schmidt, N. B., Berlim, M. T., . . Rudd, M. D. (2005). Four studies on how past and current suicidiality relate even when "everything but the kitchen sink" is covered. Journal of Abnormal Psychology, 114, 291303. doi:10.1037/0021-843.X.114.2.291

Konrad, N. (2001). Psychiatry in custody and prisons. In F. Henn, N. Sartorius, H. Helmchen, \& H. Lauder (Eds.), Contemporary Psychiatry (Vol. 2., pp. 319-336). Heidelberg: Springer.

Laishes, J. (1997). Inmate suicides in the correctional service of Canada. Crisis, 18, 157-162. doi:10.1027/0227-5910.18.4.157

Leknes, S., Brooks, J. C. W., Wiech, K., \& Tracey, I. (2008). Pain relief as an opponent process: A psychophysical investigation. European Journal of Neuroscience, 28, 794-801. doi: $10.1111 /$ j.1460-9568.2008.06380.x

Lewinsohn, P. M., Rohde, P., \& Seeley, J. R. (1994). Psychological risk factors for future 
adolescent suicide attempts. Journal of Counseling and Clinical Psychology, 62, 297-305. doi:10.1037/0022-006X.62.2.297

Linehan, M. M. (1981). The suicidal behaviors questionnaire (SBQ). Unpublished instrument, University of Washington, Seattle.

Marcus, P., \& Alcabes, P. (1993). Characteristics of suicides by inmates in an urban jail. Hospital \& Community Psychology, 44, 256-261.

Marcus, D. K., Hamlin, R. J., \& Lyons, P. M. (2001). Negative affect and interpersonal rejection among prison inmates in a therapeutic community: A social relations analysis. Journal of Abnormal Psychology, 110, 544-552. doi:10.137//0021-843X.110.4.544

McIntosh, J. L., \& Drapeau, C. W. (for the American Association of Suicidology). (2012). U.S.A. suicide 2010: Official final data. Retrieved from the American Association of Suicidology website: http://www.suicidology.org.

Messina, N. P., Burdon, W. M., \& Prendergast, M. L. (2003). Assessing the needs of women in institutional therapeutic communities. Journal of Offender Rehabilitation, 37, 89-106.

Mills, J. F., \& Kroner. D. G. (2005). Screening for suicide risk factors in prison inmates: Evaluating the efficiency of the depression, hopelessness and suicide screening form (DHS). Legal and Criminological Psychology, 10, 1-12. doi:10.1348/135532504X15295

Mills, J. F., \& Kroner, D. G. (2006). Impression management and self-report among violent offenders. Journal of Interpersonal Violence, 21, 178-192. doi:10.1177/088626505282288

Mitichison, S., Rix, K. J., Renvoize, E. B., \& Schweiger, M. (1994). Recorded psychiatric morbidity in a large prison for male remanded and sentenced prisoners. Medicine, Science, and the Law, 34, 324-330. 
Mosicicki, E. K. (1995). Epidemiology of suicidal behavior. Suicide and Life Threatening Behavior, 25, 22-35.

Mumola, C. J. (2005). Suicide and homicide in state prisons and local jails. Bureau of Justice Statistics Special Report, 1-12. Retrieved from http://www.prisonpolicy.org/scans/bjs/shsplj.pdf

Murphy, G. E., \& Wetzel, R. D. (1990). The lifetime risk of suicide in alcoholism. Archives of General Psychiatry, 47, 383-392.

National Institute of Mental Health (2011). Suicide in the U.S.: Statistics and prevention. Retrieved from the National Institute of Mental Health website: http://www.nimh.nih.gov

Nazem, S., Gregg, J., Baker, E., \& Fiske, A. (2012, April). A preliminary test of the interpersonal-psychological theory in an incarcerated population. Paper presented at the meeting of the American Association of Suicidology, Baltimore, MD.

Nock, M. K., Joiner, T. E., Gordon, K. H., Lloyd-Richardson, E., \& Prinstein, M. J. (2006). Nonsuicidal self-injury among adolescents: Diagnostic correlates and relation to suicide attempts. Psychiatry Research, 144, 65-72. doi: 10.1016/j.psychres.2006.05.010

Novick, L. F., \& Remmlinger, E. (1978). A study of 128 deaths in New York City correctional facilities (1971-1976): Implications for prisoner health care. Medical Care, XVI, 749-756. Retrieved from http://www.jstor.org/stable/3763505

O’Driscoll, C., Samuels, A., \& Zacka, M. (2007). Suicide in New South Wales prisons, 1995 2005: Towards a better understanding. Australian and New Zealand Journal of Psychiatry, 41, 519-524. 
Orbach, I., Stein, D., Palgi, Y., Asherov, J., Har-Even, D., \& Elizur, A. (1996). Perception of physical pain in accident and suicide attempt patients: Self-preservation vs selfdestruction. Journal of Psychiatric Research, 30, 307-320.

Orbach, I., Mikulincer, M., King, R., Cohen, D., \& Stein, D. (1997). Thresholds and tolerance of physical pain in suicidal and nonsuicidal adolescents. Journal of Counseling and Clinical Psychology, 65, 646-652.

Osman, A., Bagge, C. L., Gutierrez, P. M., Konick, L. C., Kopper, B. A., \& Barrios, F. X. (2001). The suicidal behaviors questionnaire-revised (SBQ-R): Validation with clinical and nonclinical samples. Assessment, 8, 443-454.

Palmer, E. J., \& Connelly, R. (2005). Depression, hopelessness and suicide ideation among vulnerable prisoners. Criminal Behaviour and Mental Health, 15, 164-170. doi:10.1002/cbm.4

Patrick, C. J., Bradley, M. M., \& Lang, P. J. (1993). Emotion in the criminal psychopath: Startle reflex modulation. Journal of Abnormal Psychology, 102, 82-92.

Patton, J. H., Stanford, M. S., Baratt, E. S. (1995). Factor structure of the barratt impulsive scale. Journal of Clinical Psychology, 51, 768-774.

Perry, A. E., Marandos, R., Coulton, S., \& Johnson, M. (2010). Screening tools assessing risk of suicide and self-harm in adult offenders: A systematic review. International Journal of Offender Therapy and Comparative Criminology, 54, 803-828.

doi:10.1177/0306624X09359757

Rabe, K. (2012). Prison structure, inmate mortality and suicide risk in Europe. International Journal of Law and Psychiatry, 35, 222-230. doi: 10.1016/j.ijlp.2012.02.012 
Radloff, L. S. (1977). The ces-d scale: A self-report depression scale for research in the general population. Applied Psychological Measurement, 1, 385-401. doi:10.1177/014662167700100306

Ribeiro, J. D., \& Joiner, T. E. (2009). The interpersonal-psychological theory of suicidal behavior: Current status and future directions. Journal of Clinical Psychology, 65, 12911299. doi:10.1002/jclp.20621

Rihmer, Z., Belso, N., \& Kiss, K. (2002). Strategies for suicide prevention. Current Opinion in Psychiatry, 15, 83-87. Retrieved from http://www.lefnet.hu

Rossotto, E., Yager, J., Rorty, M. (1998). The impulsive behavior scale. In: J. Vanderlinden, W. Vandereycken (Eds.), Trauma, dissociation, and impulse dyscontrol in eating disorders. Brunner/Mazel, Levittown, PA.

Roy, A., \& Linnoila, M. (1986). Alcoholism and suicide. Suicide and Life Threatening Behavior, $16,244-273$.

Salive, M. E., Smith, G. S., \& Brewer, T. F. (1989). Suicide mortality in the Maryland state prison system, 1979 through 1987. JAMA, 262, 365-369. Retrieved from http://www.jama.ama-assn.org

Sarchiapone, M., Jovanovic, N., Roy, A., Podlesek, A., Carli, V., Amore, M., .. Marusic, A. (2009). Relations of psychological characteristics to suicide behaviour: Results from a large sample of male prisoners. Personal and Individual Differences, 47, 250-255. doi:10.1016/j/paid.2009.03.008

Shaw, J., Baker, D., Hunt, I. M., Moloney, A., \& Appleby, L. (2004). Suicide by prisoners: National clinical survey. British Journal of Psychiatry, 184, 263-267. doi: 10.1192/bjp.184.3.263 
Sher, L. (2006). Alcoholism and suicidal behavior: A clinical overview. Acata Psychiatrica Scandinavica, 113, 13-22. doi:10.1111/j.1600-0447.2005.00643.x

Sher, L., Oquendo, M. A., \& Mann, J. J. (2001). Risk of suicide in mood disorders. Clinical Neuroscience Research, 1, 337-344. doi: 10.1016/S1566-2772(01)00035-4

Solomon, R. L. (1980). The opponent-process theory of acquired motivation: The costs of pleasure and the benefits of pain. American Psychologist, 35, 691-712.

Solomon, R. L., \& Corbit, J. D. (1974). An opponent-process theory of motivation: Temporal dynamics of affect. Psychological Review, 81, 119-145.

Smith, P. N., Cukrowicz, K. C., Poindexter, E. K., Hobson, V., \& Cohen, L. M. (2010). The acquired capability for suicide: A comparison of suicide attempters, suicide ideators, and non-suicidal controls. Depression and Anxiety, 27, 871-877. doi:10.1002/da.20701

Suto, I., \& Arnaut, G. L. Y. (2010). Suicide in prison: A qualitative study. The Prison Journal, 90, 288-312. doi:10.1177/0032885510373499

Tabachnick, B. G., \& Fidell, L. S. (2007). Using multivariate statistics. Boston, MA: Pearson Education, Inc.

United States Federal Bureau of Prisons (2011). Annual data summary 1990-2019. Washington D.C., Federal Bureau of Prisons.

Van Orden, K. A., Cukrowicz, K. C., Witte, T. K., \& Joiner, T. E. (2012). Thwarted belongingness and perceived burdensomeness: Construct validity and psychometric properties of the interpersonal needs questionnaire. Psychological Assessment, 24, 197 215. doi:10.1037/a0025358 
Van Orden, K. A., Witte, T. K., Cukrowicz, K. C., Braithwaite, S. R., Selby, E. A., \& Joiner, T. E. (2010). The interpersonal theory of suicide. Psychological Review, 117, 575-600. doi:10.1037/a0018697

Van Orden, K. A., Witte, T. K., Gordon, K. H., Bender, T. W., \& Joiner, T. E. (2008). Suicidal desire and the capability for suicide: Tests of the interpersonal-psychological theory of suicidal behavior among adults. Journal of Counseling and Clinical Psychology, 1, 72-83. doi:10.1037/0022-006X.76.1.72

Verona, E., Patrick, C. J., \& Joiner, T. E. (2001). Psychopathy, antisocial personality, and suicide risk. Journal of Abnormal Psychology, 110, 462-470. doi:10.1037//0021-843X.110.3.462

von Hippel PT. (2009) How to impute squares, interactions, and other transformed variables. Sociological Methodology, 39, 265-91.

Way, B. B., Miraglia, R., Sawyer, D. A., Beer, R., \& Eddy, J. (2005). Factors related to suicide in New York state prisons. Journal of Law and Psychiatry, 28, 207-221. doi:10.1016/j.ijlp.2004.09.003

Whiteside, S. P., \& Lynam, D. R. (2001). The five factor model and impulsivity: Using a structural model of personality to understand impulsivity. Personality and Individual Differences, 30, 669-689.

Zitzmann, M., \& Nieschlag, E. (2001). Testosterone levels in health men and the relation to behavioural and physical characteristics: Facts and constructs. European Journal of Endocrinology, 144, 183-197. doi: 10.1530/eje.0.1440183

Zlotnick, C., Clarke, J. G., Friedmann, P. D., Roberts, M. B., Sacks, S., \& Melnick, G. (2008). Gender differences in comorbid disorders among offenders in prison substance abuse treatment programs. Behavioral Sciences and the Law, 26, 403-412. doi:10.1002/bsl.831 
Table 1

Participant Characteristics by Group

\begin{tabular}{|c|c|c|c|c|c|c|c|c|}
\hline \multirow[b]{2}{*}{ Variable } & \multicolumn{2}{|c|}{ Inmates } & \multicolumn{2}{|c|}{ Community Controls } & \multirow[b]{2}{*}{ t or $\chi^{2}$} & \multirow[b]{2}{*}{ df } & \multicolumn{2}{|c|}{$\begin{array}{c}\text { Previously-Incarcerated } \\
\text { Controls }{ }^{1}\end{array}$} \\
\hline & $\mathrm{n}$ & $\mathrm{M}(\mathrm{SD}) / \%$ & $\mathrm{n}$ & $\mathrm{M}(\mathrm{SD}) / \%$ & & & $\mathrm{n}$ & $\mathrm{M}(\mathrm{SD}) / \%$ \\
\hline Age & 114 & $40.18(9.87)$ & 94 & $39.35(12.33)$ & 0.52 & 176.84 & 15 & $39.20(11.87)$ \\
\hline Education & 112 & $12.29(2.28)$ & 96 & $15.91(2.96)$ & $-9.95 * * *$ & 176.84 & 15 & $13.93(2.19)$ \\
\hline \multicolumn{9}{|l|}{ Race } \\
\hline American Indian & 0 & $0 \%$ & 1 & $1.04 \%$ & \multirow{5}{*}{$52.57 * * *$} & \multirow{5}{*}{4} & 2 & $13.33 \%$ \\
\hline Asian & 3 & $2.63 \%$ & 1 & $1.04 \%$ & & & 0 & $0 \%$ \\
\hline Black & 54 & $47.37 \%$ & 4 & $4.17 \%$ & & & 2 & $13.33 \%$ \\
\hline White & 57 & $50.00 \%$ & 88 & $91.67 \%$ & & & 11 & $73.33 \%$ \\
\hline Other & 0 & $0 \%$ & 2 & $2.08 \%$ & & & 0 & $0 \%$ \\
\hline \multicolumn{9}{|l|}{ Ethnicity } \\
\hline Non-Hispanic/Non-Latino & 100 & $87.72 \%$ & 88 & $98.88 \%$ & \multirow[t]{2}{*}{$9.09 * *$} & \multirow[t]{2}{*}{1} & 13 & $92.86 \%$ \\
\hline Hispanic/Latino & 14 & $12.28 \%$ & 1 & $1.12 \%$ & & & 1 & $7.14 \%$ \\
\hline \multicolumn{9}{|l|}{ Marital Status } \\
\hline Divorced & 8 & $7.21 \%$ & 3 & $3.13 \%$ & \multirow{4}{*}{$19.78 * * *$} & \multirow{4}{*}{3} & 1 & $6.67 \%$ \\
\hline Married & 42 & $37.84 \%$ & 66 & $68.75 \%$ & & & 8 & $53.33 \%$ \\
\hline Separated & 4 & $3.60 \%$ & 2 & $2.08 \%$ & & & 1 & $6.67 \%$ \\
\hline Single & 57 & $51.35 \%$ & 25 & $26.04 \%$ & & & 5 & $33.33 \%$ \\
\hline
\end{tabular}


Table 2

Descriptive Statistics by Group

\begin{tabular}{|c|c|c|c|c|c|c|c|}
\hline \multirow[b]{2}{*}{ Variable } & \multicolumn{2}{|c|}{ Inmates } & \multicolumn{2}{|c|}{$\begin{array}{l}\text { Community } \\
\text { Controls }\end{array}$} & & \multicolumn{2}{|c|}{$\begin{array}{c}\text { Previously- } \\
\text { Incarcerated Controls } 1\end{array}$} \\
\hline & $\mathrm{M}$ & SD & $\mathrm{M}$ & $\mathrm{SD}$ & $t(208)$ & $\mathrm{M}$ & SD \\
\hline $\begin{array}{l}\text { Perceived } \\
\text { Burdensomeness }\end{array}$ & 8.63 & 4.23 & 7.86 & 3.94 & -1.54 & 10.00 & 4.85 \\
\hline $\begin{array}{l}\text { Thwarted } \\
\text { Belongingness }\end{array}$ & 20.13 & 10.49 & 18.47 & 9.42 & -1.19 & 23.07 & 11.89 \\
\hline $\begin{array}{l}\text { Acquired } \\
\text { Capability }\end{array}$ & 42.86 & 11.56 & 49.52 & 9.43 & $4.50 * * *$ & 52.33 & 10.49 \\
\hline $\begin{array}{l}\text { Depressive } \\
\text { Symptoms }\end{array}$ & 14.05 & 9.99 & 9.77 & 8.05 & $-3.35 * * *$ & 14.15 & 12.01 \\
\hline Suicidal Risk ${ }^{2}$ & 3.50 & 1.39 & 4.27 & 2.15 & $3.10 * *$ & 4.07 & 2.03 \\
\hline Total Events & 89.59 & 18.28 & 85.92 & 15.70 & -1.50 & 98.43 & 13.57 \\
\hline
\end{tabular}

Note. Inmates $(\mathrm{n}=114)$, Community Controls $(\mathrm{n}=96)$, Previously-Incarcerated Controls $(\mathrm{n}=$ 15). ${ }^{* *} \mathrm{p}<.01 . * * * \mathrm{p}<.001,{ }^{1}$ Descriptive information on previously-incarcerated controls is included for information only. ${ }^{2}$ Means and SD are provided for non-transformed values. 
Table 3

SBQR Items by Group

\begin{tabular}{lccc}
\hline \multicolumn{1}{c}{ Item } & Inmates & $\begin{array}{c}\text { Community } \\
\text { Controls }\end{array}$ & $\begin{array}{c}\text { Previously- } \\
\text { Incarcerated } \\
\text { Controls }\end{array}$ \\
\cline { 2 - 4 } & & $\%$ & $\%$ \\
\hline Thought/Attempted Suicide & $\%$ & $61.46 \%$ & $73.33 \%$ \\
Never & $89.47 \%$ & $28.13 \%$ & $13.33 \%$ \\
Brief passing thought & $7.89 \%$ & $9.38 \%$ & $6.67 \%$ \\
Plan for suicide & $1.75 \%$ & $1.04 \%$ & $6.67 \%$ \\
Attempted Suicide & $0.88 \%$ & & \\
Frequency of SI in past year & & $73.33 \%$ & $86.67 \%$ \\
Never & $90.35 \%$ & $11.46 \%$ & $6.67 \%$ \\
Rarely (1 time) & $5.26 \%$ & $2.08 \%$ & $6.67 \%$ \\
Sometimes (2 times) & $2.63 \%$ & $1.04 \%$ & $0 \%$ \\
Often (3-4 times) & $1.75 \%$ & $2.08 \%$ & $0 \%$ \\
Very Often (5 or more times) & $0 \%$ & & \\
Told someone about suicide plan & & $87.50 \%$ & $63.33 \%$ \\
No & $97.37 \%$ & $9.38 \%$ & $0.67 \%$ \\
Yes (one time) & $1.75 \%$ & $3.13 \%$ & $0 \%$ \\
Yes (more than once) & $0.88 \%$ & & \\
Likelihood of attempt someday & & $84.21 \%$ & $06.67 \%$ \\
Never & $86.73 \%$ & $4.21 \%$ & $0.67 \%$ \\
No chance at all & $9.73 \%$ & $7.37 \%$ & $0 \%$ \\
Rather unlikely & $3.54 \%$ & $4.21 \%$ & $0 \%$ \\
Likely & $0 \%$ & $0 \%$ & \\
Rather likely & $0 \%$ & & $0 \%$ \\
Very likely & $0 \%$ & & \\
\hline
\end{tabular}


Table 4

Pooled Correlation Coefficients - Inmates $(n=114)$

\begin{tabular}{|c|c|c|c|c|c|c|c|c|c|c|}
\hline Variable & 1 & 2 & 3 & 4 & 5 & 6 & 7 & 8 & 9 & 10 \\
\hline 1. Age & - & $.21 * * *$ & .06 & $.22 * * *$ & $-.12 * *$ & $.13^{* *}$ & .08 & -.01 & $-.13 * *$ & -.07 \\
\hline 2. Edu & & - & $-.22 * * *$ & $-.24 * * *$ & -.06 & $-.15 * * *$ & .08 & $-.12 * *$ & $-.14 * *$ & $-.15 * * *$ \\
\hline 3. Burd & & & - & $.61 * * *$ & -.08 & $.45^{* * * *}$ & $.38 * * *$ & $.19 * * *$ & $.21 * * *$ & $.23 * * *$ \\
\hline 4. Belong & & & & - & -.03 & $.57 * * *$ & $.23 * * *$ & $.26 * * *$ & $.23 * * *$ & $.28 * * *$ \\
\hline 5.ACSS & & & & & - & -.02 & .01 & $.21 * * *$ & $.34 * * *$ & $.30 * * *$ \\
\hline 6. CESD & & & & & & - & $.42 * * *$ & $.34 * * *$ & $.29 * * *$ & $.37 * * *$ \\
\hline 7. SBQR & & & & & & & - & $.14 * * *$ & $.31 * * *$ & $.25 * * *$ \\
\hline 8. IBS & & & & & & & & - & $.52 * * *$ & $.90 * * *$ \\
\hline 9. PPES & & & & & & & & & - & $.83 * * *$ \\
\hline 10. Events & & & & & & & & & & - \\
\hline
\end{tabular}

Note. ${ }^{* *} \mathrm{p}<.01 . * * * \mathrm{p}<.001 . N$ 's vary slightly due to missing data on education. 
Table 5

Pooled Correlation Coefficients - Community Controls $(n=96)$

\begin{tabular}{|c|c|c|c|c|c|c|c|c|c|c|}
\hline Variable & 1 & 2 & 3 & 4 & 5 & 6 & 7 & 8 & 9 & 10 \\
\hline 1. Age & - & $-.19 * * *$ & .07 & $.10 *$ & $-.18 * * *$ & $-.10 *$ & -.08 & $-.11 *$ & -.01 & -.07 \\
\hline 2. Edu & & - & -.02 & .06 & .01 & $-.19 * * *$ & .02 & $-.12 * *$ & -.06 & $-.10 *$ \\
\hline 3. Burd & & & - & $.56 * * *$ & $-.10 *$ & $.56 * * *$ & $.62 * * *$ & $.32 * * *$ & $.29 * * *$ & $.34 * * *$ \\
\hline 4. Belong & & & & - & -.03 & $.57 * * *$ & $.49 * * *$ & $.31 * * *$ & $.21 * * *$ & $.29 * * *$ \\
\hline 5.ACSS & & & & & - & $-.14 * *$ & $.10^{*}$ & $.11^{*}$ & $.20 * * *$ & $.17 * * *$ \\
\hline 6. CESD & & & & & & - & $.50 * * *$ & $.39 * * *$ & $.33 * * *$ & $.40 * * *$ \\
\hline 7. SBQR & & & & & & & - & $.53 * * *$ & $.51 * * *$ & $.57 * * *$ \\
\hline 8. IBS & & & & & & & & - & $.68 * * *$ & $.93 * * *$ \\
\hline 9. PPES & & & & & & & & & - & $.90 * * *$ \\
\hline 10. Events & & & & & & & & & & - \\
\hline
\end{tabular}

Note. $* \mathrm{p}<.05$. $* * \mathrm{p}<.01 . * * * \mathrm{p}<.001$. 
Table 6

Pooled Correlation Coefficients - Previously-Incarcerated Controls $(n=15)$

\begin{tabular}{|c|c|c|c|c|c|c|c|c|c|c|}
\hline Variable & 1 & 2 & 3 & 4 & 5 & 6 & 7 & 8 & 9 & 10 \\
\hline 1. Age & - & .15 & .19 & -.16 & $-.34 * *$ & .03 & .05 & .12 & .11 & .13 \\
\hline 2. Edu & & - & $.29 *$ & .08 & .02 & $.36^{* *}$ & .11 & $.37 * *$ & -.13 & .15 \\
\hline 3. Burd & & & - & $.87 * * *$ & $-.34 * *$ & $.76 * * *$ & $.52 * * *$ & -.02 & $-.27 *$ & -.15 \\
\hline 4. Belong & & & & - & $-.26^{*}$ & $.74 * * *$ & $.52 * * *$ & -.04 & $-.34 * *$ & -.21 \\
\hline 5.ACSS & & & & & - & $-.46 * * *$ & -.13 & .10 & $.37 * *$ & $.25^{*}$ \\
\hline 6. CESD & & & & & & - & $.59 * * *$ & -.04 & $-.40 * * *$ & $-.23 *$ \\
\hline 7. SBQR & & & & & & & - & -.04 & $-.27 *$ & -.17 \\
\hline 8. IBS & & & & & & & & - & $.62 * * *$ & $.91 * * *$ \\
\hline 9. PPES & & & & & & & & & - & $.89 * * *$ \\
\hline 10. Events & & & & & & & & & & - \\
\hline
\end{tabular}

Note. $* \mathrm{p}<.05 . * * \mathrm{p}<.01 . * * * \mathrm{p}<.001$. 
Table 7

Principal-Components Analysis with Varimax Rotation and Descriptive Statistics $(n=114)$

\begin{tabular}{lccccc}
\hline \multicolumn{1}{c}{ Factor } & $\begin{array}{c}\% \text { of } \\
\text { Variance }\end{array}$ & Range & Mean & SD & $\begin{array}{c}\text { Cronbach } \\
\text { Alpha }\end{array}$ \\
\hline 1: Illegal painful and provocative events & $15.92 \%$ & $14-51$ & 30.53 & 9.15 & 0.84 \\
2: Legal painful and provocative events & $8.71 \%$ & $15-51$ & 27.44 & 7.66 & 0.81 \\
3: Suicidal behaviors & $6.81 \%$ & $5-20$ & 10.33 & 3.25 & 0.70 \\
4: Abuse and bodily injury & $4.78 \%$ & $6-28$ & 10.78 & 3.73 & 0.62 \\
\hline
\end{tabular}


Table 8

Items and Factor Loadings for Varimax Orthogonal Factor Solution for Impulsive, Painful, and Provocative Events $(n=114)$

\begin{tabular}{|c|c|c|c|c|}
\hline \multirow[t]{2}{*}{ Items } & \multicolumn{4}{|c|}{ Factor Loadings } \\
\hline & 1 & 2 & 3 & 4 \\
\hline IBS4. Consumed too much alcohol & .439 & .253 & .310 & .106 \\
\hline IBS5. Sex w/someone when you didn't want to & .415 & .407 & -.045 & -.011 \\
\hline IBS10. Stolen (family, friends) & .538 & -.099 & .154 & -.093 \\
\hline IBS11. Driven under the influence & .592 & .350 & .206 & .006 \\
\hline IBS13. Engaged in unsafe sex & .679 & .179 & .051 & .104 \\
\hline IBS16. Eaten food in store before purchasing & .473 & .373 & .023 & -.281 \\
\hline IBS17. Recreational drugs & .462 & .133 & .375 & -.144 \\
\hline IBS19. Driven recklessly & .513 & .407 & .133 & -.075 \\
\hline IBS20. Stolen (store, vendor) & .556 & -.092 & .218 & -.185 \\
\hline IBS22. Impulsively spent money & .496 & .195 & -.051 & .211 \\
\hline IBS25. Stolen food & .501 & .096 & -.020 & -.194 \\
\hline PPES16. Been arrested & .603 & .021 & -.145 & .094 \\
\hline PPES19. Participated in illegal activity & .703 & .140 & -.102 & .190 \\
\hline IBS6. Daredevil/take risks & .457 & .480 & .170 & .117 \\
\hline IBS14. Been accident prone & .207 & .519 & .249 & .019 \\
\hline IBS18. Push self physically to the limit & .275 & .488 & .160 & .275 \\
\hline IBS21. Hurt self regularly (unintentional) & .202 & .426 & .081 & -.073 \\
\hline IBS24. Enjoy risks or dangerous activities & .405 & .493 & .093 & .247 \\
\hline PPES1. Gone skydiving & -.330 & .476 & .120 & .399 \\
\hline PPES2. Gone rock climbing & -.220 & .538 & .337 & .124 \\
\hline PPES11. Shot a gun & .128 & .488 & -.069 & .048 \\
\hline PPES12. Tied a noose & -.018 & .416 & .168 & .230 \\
\hline PPES17. Dissected animals & .088 & .437 & .069 & .144 \\
\hline PPES18. Gone bungee jumping & -.135 & .515 & .091 & -.128 \\
\hline PPES20. Been in physical fights & .316 & .416 & -.303 & .308 \\
\hline PPES21. Jumped from high places & .230 & .554 & .046 & -.036 \\
\hline PPES23. Been stabbed & .109 & .453 & -.196 & .037 \\
\hline PPES24. Been shot & .077 & .401 & -.065 & .038 \\
\hline IBS1. Overdosed on drugs & .056 & -.057 & .720 & -.091 \\
\hline IBS3. Self-mutilation thoughts \& impulses & .126 & .145 & .593 & -.065 \\
\hline IBS7. Non-lethal suicide gestures & -.047 & .071 & .711 & .199 \\
\hline IBS23. Self-mutilation behaviors & .051 & .055 & .646 & .160 \\
\hline PPES10. Imagined killing self & -.121 & -.038 & .578 & .490 \\
\hline PPES4. Tattoo & .280 & -.057 & -.148 & .462 \\
\hline PPES6. Victim of physical abuse & -.092 & .094 & .271 & .665 \\
\hline PPES7. Victim of sexual abuse & -.107 & -.066 & .026 & .615 \\
\hline PPES8.Witness of physical abuse & .116 & .193 & .114 & .595 \\
\hline PPES13. Surgery & -.061 & .200 & -.169 & .515 \\
\hline
\end{tabular}




\begin{tabular}{lcccc} 
PPES22. Injuries requiring medical attention & .109 & .382 & .068 & $\mathbf{. 4 7 7}$ \\
IBS2. Sexually "promiscuous" & .276 & -.023 & .076 & .222 \\
IBS8. Went to doctor/hospital for self-harm & -.157 & -.125 & .063 & -.122 \\
IBS9. Abused laxatives, diuretics, diet pills & .114 & .250 & .296 & -.177 \\
IBS12. Suicide attempts & -.286 & .216 & .163 & .197 \\
IBS15. Suicidal ideation & -.141 & -.016 & .338 & .314 \\
PPES3. Participated in contact sports & .252 & .287 & -.197 & .336 \\
PPES5. Piercing & .210 & -.268 & -.096 & .362 \\
PPES9. Witness sexual abuse & -.209 & .288 & .044 & .214 \\
PPES14. IV drug use & .342 & .050 & .568 & -.229 \\
PPES15. Broken bone & -.087 & .355 & -.018 & .343 \\
\hline
\end{tabular}

Note. Boldface indicates final factor loading decision. 
Table 9

EFA Factors Predicting Acquired Capability for Suicide

\begin{tabular}{lccccc}
\hline \multicolumn{1}{c}{ Factor } & $R^{2}$ & $B$ & $S E$ & $t$ & $\mathrm{P}$ \\
\hline Illegal painful and provocative events & $\mathbf{0 . 0 5}$ & $\mathbf{0 . 2 9}$ & $\mathbf{0 . 1 2}$ & $\mathbf{2 . 5 0}$ & $<.05$ \\
Legal painful and provocative events & $\mathbf{0 . 1 5}$ & $\mathbf{0 . 5 8}$ & $\mathbf{0 . 1 3}$ & $\mathbf{4 . 4 3}$ & $<.001$ \\
Suicidal behaviors & $\mathbf{0 . 0 6}$ & $\mathbf{0 . 8 6}$ & $\mathbf{0 . 3 3}$ & $\mathbf{2 . 6 4}$ & $<.05$ \\
Abuse and bodily injury & 0.02 & 0.45 & 0.29 & 1.54 & .13 \\
\hline
\end{tabular}




\section{Appendix A}

ACSS

Please read each item below and indicate to what extent you feel the statement describes you. Rate each statement using the scale below and then write your response next to the item.

0

Not at all

like me
12

2

3

4

Very much

like me

1. Things that scare most people do not scare me.

2. The sight of my own blood does not bother me.

3. I avoid certain situations (e.g., certain sports) because of the possibility of injury.

4. I can tolerate a lot more pain than most people.

5. People describe me as fearless.

6.The sight of blood bothers me a great deal.

7. The fact that I am going to die does not affect me.

8. The pain involved in dying frightens me.

9. Killing animals in a science course would not bother me.

10. I am very much afraid to die.

11. It does not make me nervous when people talk about death.

12. The sight of a dead body is horrifying to me.

13. The prospect of my own death arouses anxiety in me.

14.I am not disturbed by death being the end of life as I know it.

15. I like watching the aggressive contact in sports games.

16. The best parts of hockey games are the fights.

17. When I see a fight, I stop to watch.

18. I prefer to shut my eyes during the violent parts of movies.

19. I am not at all afraid to die.

20. I could kill myself if I wanted to. (Even if you have never wanted to kill yourself, please answer this question.) 


\section{Appendix B}

IBS

Please answer the following questions for any time in the past.

For each question circle $\mathbf{O N E}$ answer.

\begin{tabular}{|c|c|c|c|c|c|c|}
\hline & & Never & Once & $\begin{array}{c}\text { On } \\
\text { Occasion }\end{array}$ & Sometimes & Regularly \\
\hline 1. & $\begin{array}{l}\text { Have you ever overdosed on } \\
\text { prescription or illegal drugs? }\end{array}$ & 1 & 2 & 3 & 4 & 5 \\
\hline 2. & $\begin{array}{l}\text { Have you been sexually } \\
\text { "promiscuous"? }\end{array}$ & 1 & 2 & 3 & 4 & 5 \\
\hline 3. & $\begin{array}{l}\text { Have you had any self-mutilation } \\
\text { thoughts and impulses (without } \\
\text { taking action)? }\end{array}$ & 1 & 2 & 3 & 4 & 5 \\
\hline 4. & $\begin{array}{l}\text { Have you had times when you've } \\
\text { consumed too much alcohol for } \\
\text { your own good? }\end{array}$ & 1 & 2 & 3 & 4 & 5 \\
\hline 5. & $\begin{array}{l}\text { Have you had sex with someone } \\
\text { you didn't necessarily want to } \\
\text { have sex with? }\end{array}$ & 1 & 2 & 3 & 4 & 5 \\
\hline 6. & $\begin{array}{l}\text { Have people told you that you're } \\
\text { a daredevil type or that you take } \\
\text { too many risks? }\end{array}$ & 1 & 2 & 3 & 4 & 5 \\
\hline 7. & $\begin{array}{l}\text { Have you had any suicide } \\
\text { gestures (non -lethl)? }\end{array}$ & 1 & 2 & 3 & 4 & 5 \\
\hline 8. & $\begin{array}{l}\text { Have you been to the doctor or } \\
\text { hospital as a result of a self-harm } \\
\text { incident? }\end{array}$ & 1 & 2 & 3 & 4 & 5 \\
\hline 9. & $\begin{array}{l}\text { Have you had abused laxatives, } \\
\text { diuretics or diet pills? }\end{array}$ & 1 & 2 & 3 & 4 & 5 \\
\hline & $\begin{array}{l}\text { Have you stolen personal items or } \\
\text { money from acquaintances, } \\
\text { friends or family? }\end{array}$ & 1 & 2 & 3 & 4 & 5 \\
\hline 11. & $\begin{array}{l}\text { Have you driven under the } \\
\text { influence of drugs and/or alcohol? }\end{array}$ & 1 & 2 & 3 & 4 & 5 \\
\hline & $\begin{array}{l}\text { Have you made any suicide } \\
\text { attempts? }\end{array}$ & 1 & 2 & 3 & 4 & 5 \\
\hline 13. & Have you engaged in unsafe sex? & 1 & 2 & 3 & 4 & 5 \\
\hline & $\begin{array}{l}\text { Have you been accident prone, } \\
\text { that is been in accidents } \\
\text { regularly? }\end{array}$ & 1 & 2 & 3 & 4 & 5 \\
\hline & $\begin{array}{l}\text { Have you had any suicidal } \\
\text { thoughts and impulses (without } \\
\text { taking action)? }\end{array}$ & 1 & 2 & 3 & 4 & 5 \\
\hline
\end{tabular}




\begin{tabular}{|c|c|c|c|c|c|c|}
\hline & & Never & Once & $\begin{array}{c}\text { On } \\
\text { Occasion }\end{array}$ & Sometimes & Regularly \\
\hline 16. & $\begin{array}{l}\text { Have you eaten food in a grocery } \\
\text { market before having the chance } \\
\text { to pay for it? }\end{array}$ & 1 & 2 & 3 & 4 & 5 \\
\hline 17. & $\begin{array}{l}\text { Have you had times when you've } \\
\text { taken too many recreational } \\
\text { drugs? }\end{array}$ & 1 & 2 & 3 & 4 & 5 \\
\hline 18. & $\begin{array}{l}\text { Have you been known to push } \\
\text { yourself physically to the limit? }\end{array}$ & 1 & 2 & 3 & 4 & 5 \\
\hline 19. & Have you driven recklessly? & 1 & 2 & 3 & 4 & 5 \\
\hline & $\begin{array}{l}\text { Have you stolen material goods } \\
\text { (such as clothes or jewelry) from } \\
\text { a store or vender? }\end{array}$ & 1 & 2 & 3 & 4 & 5 \\
\hline & $\begin{array}{l}\text { Have you hurt yourself regularly, } \\
\text { even if you didn't mean to (e.g. } \\
\text { falling, bruising)? }\end{array}$ & 1 & 2 & 3 & 4 & 5 \\
\hline & $\begin{array}{l}\text { Have you impulsively spent } \\
\text { money on clothes, jewelry or } \\
\text { other items? }\end{array}$ & 1 & 2 & 3 & 4 & 5 \\
\hline & $\begin{array}{l}\text { Have you self-mutilated (e.g., } \\
\text { cutting, pinching, burning } \\
\text { yourself)? }\end{array}$ & 1 & 2 & 3 & 4 & 5 \\
\hline & $\begin{array}{l}\text { Have you often enjoyed taking } \\
\text { risks or engaging in somewhat } \\
\text { dangerous activity? }\end{array}$ & 1 & 2 & 3 & 4 & 5 \\
\hline
\end{tabular}




\section{Appendix C}

PPES

Please answer the following questions for any time in the past.

For each question circle $\mathbf{O N E}$ answer.

\begin{tabular}{|c|c|c|c|c|c|c|}
\hline & & Never & Once & $\begin{array}{c}\text { On } \\
\text { Occasion }\end{array}$ & Sometimes & Regularly \\
\hline 1. & Have you gone skydiving? & 1 & 2 & 3 & 4 & 5 \\
\hline 2. & Have you gone rock climbing? & 1 & 2 & 3 & 4 & 5 \\
\hline 3. & $\begin{array}{l}\text { Have you participated in contact } \\
\text { sports (e.g., tackle football, } \\
\text { hockey, wrestling, martial arts)? }\end{array}$ & 1 & 2 & 3 & 4 & 5 \\
\hline 4. & Did you get a tattoo? & 1 & 2 & 3 & 4 & 5 \\
\hline 5. & Did you get a piercing? & 1 & 2 & 3 & 4 & 5 \\
\hline 6. & $\begin{array}{l}\text { Have you been a victim of } \\
\text { physical abuse? }\end{array}$ & 1 & 2 & 3 & 4 & 5 \\
\hline 7. & $\begin{array}{l}\text { Have you been a victim of sexual } \\
\text { abuse? }\end{array}$ & 1 & 2 & 3 & 4 & 5 \\
\hline 8. & $\begin{array}{l}\text { Have you been a witness to } \\
\text { physical abuse? }\end{array}$ & 1 & 2 & 3 & 4 & 5 \\
\hline 9. & $\begin{array}{l}\text { Have you been a witness to sexual } \\
\text { abuse? }\end{array}$ & 1 & 2 & 3 & 4 & 5 \\
\hline 10. & $\begin{array}{l}\text { Have you ever imagined killing } \\
\text { yourself? }\end{array}$ & 1 & 2 & 3 & 4 & 5 \\
\hline & Have you shot a gun? & 1 & 2 & 3 & 4 & 5 \\
\hline & Have you tied a noose? & 1 & 2 & 3 & 4 & 5 \\
\hline & Have you had surgery? & 1 & 2 & 3 & 4 & 5 \\
\hline & Have you used intravenous drugs? & 1 & 2 & 3 & 4 & 5 \\
\hline & Have you broken a bone? & 1 & 2 & 3 & 4 & 5 \\
\hline & Have you been arrested? & 1 & 2 & 3 & 4 & 5 \\
\hline & Have you dissected animals? & 1 & 2 & 3 & 4 & 5 \\
\hline 18. & Have you gone bungee jumping? & 1 & 2 & 3 & 4 & 5 \\
\hline & $\begin{array}{l}\text { Have you participated in illegal } \\
\text { activity (even if you didn't get } \\
\text { caught)? }\end{array}$ & 1 & 2 & 3 & 4 & 5 \\
\hline 20. & Have you been in physical fights? & 1 & 2 & 3 & 4 & 5 \\
\hline & $\begin{array}{l}\text { Have you jumped from high } \\
\text { places (e.g., cliffs, roofs, } \\
\text { balconies)? }\end{array}$ & 1 & 2 & 3 & 4 & 5 \\
\hline & $\begin{array}{l}\text { Have you had injuries requiring } \\
\text { medical attention? }\end{array}$ & 1 & 2 & 3 & 4 & 5 \\
\hline & Have you been stabbed? & 1 & 2 & 3 & 4 & 5 \\
\hline & Have you been shot? & 1 & 2 & 3 & 4 & 5 \\
\hline
\end{tabular}




\section{Appendix D}

INQ

The following questions ask you to think about yourself and other people. Please respond to each question by using your own current beliefs and experiences, NOT what you think is true in general, or what might be true for other people. Please base your responses on how you've been feeling recently. Use the rating scale to find the number that best matches how you feel and write your response next to the item. There are no right or wrong answers: we are interested in what you think and feel.

1

Not at all true for me

\section{2}

4

Somewhat

true for me
5

6 7

Very True for me

1. These days the people in my life would be better off if I were gone.

2. These days I think I give back to society.

3. These days the people in my life would be happier without me.

4. These days I think I have failed the people in my life.

5. These days I think people in my life would miss me if I went away.

6. These days I think I am a burden on society.

7. These days I think I am an asset to the people in my life.

8. These days I think my ideas, skills, or energy make a difference.

9. These days I think my death would be a relief to the people in my life.

10. These days I think I contribute to the well-being of the people in my life.

11. These days I feel like a burden on the people in my life.

12. These days I think the people in my life wish they could be rid of me.

13. These days I think I contribute to my community.

14. These days I think I make things worse for the people in my life.

15. These days I think I matter to the people in my life.

16. These days, other people care about me.

17. These days, I feel like I belong.

18. These days, I rarely interact with people who care about me.

19. These days, I am fortunate to have many caring and supportive friends.

20. These days, I feel disconnected from other people. 
21. These days, I often feel like an outsider in social gatherings.

22. These days, I feel that there are people I can turn to in times of need.

23. These days, I feel unwelcome in most social situations.

24. These days, I am close to other people.

25. These days, I have at least one satisfying interaction every day. 


\section{Appendix E}

SBQ-R

Please circle the number beside the statement or phrase that best applies to you.

1. Have you ever thought about or attempted to kill yourself? (circle only one)

1. Never

2. It was just a brief passing thought

3a. I have had a plan at least once to kill myself but did not try to do it

$3 \mathrm{~b}$. I have had a plan at least once to kill myself and really wanted to die

4a. I have attempted to kill myself, but did not want to die

4b. I have attempted to kill myself, and really hoped to die

2. How often have you thought about killing yourself in the past year? (circle only one)
1. Never
2. Rarely (1 time)
3. Sometimes (2 times)
4. Often (3-4 times)
5 . Very Often (5 or more times)

3. Have you ever told someone that you were going to commit suicide, or that you might do it? (circle only one)

\section{No}

2a. Yes, at one time, but did not really want to die

2b. Yes, at one time, and really wanted to do it

3a. Yes, more than once, but did not want to do it

3b. Yes, more than once, and really wanted to do it

4. How likely is it that you will attempt suicide someday? (circle only one)
0 . Never
1. No chance at all
2. Rather unlikely
3. Unlikely
4. Likely
5. Rather likely
6. Very likely 


\section{Appendix F}

\section{CES-D}

Below is a list of the ways you might have felt or behaved. Please tell me how often you have felt this way during the past week. For each question, circle one answer.

\begin{tabular}{|c|c|c|c|c|}
\hline \multirow[b]{2}{*}{ DURING THE PAST WEEK: } & \multicolumn{4}{|c|}{ Last Week } \\
\hline & $\begin{array}{c}\text { Rarely or } \\
\text { none of } \\
\text { the time } \\
\text { (less than } 1 \\
\text { day) }\end{array}$ & $\begin{array}{l}\text { Some or a } \\
\text { little of the } \\
\text { time } \\
\text { (1-2 days) }\end{array}$ & $\begin{array}{c}\text { Occasionally } \\
\text { or a moderate } \\
\text { amount of } \\
\text { time } \\
\text { (3-4 days) }\end{array}$ & $\begin{array}{l}\text { Most or all of } \\
\text { the time }\end{array}$ \\
\hline $\begin{array}{l}\text { 1. I was bothered by things that } \\
\text { usually don't bother me. }\end{array}$ & 0 & 1 & 2 & 3 \\
\hline $\begin{array}{l}\text { 2. I did not feel like eating; my } \\
\text { appetite was poor. }\end{array}$ & 0 & 1 & 2 & 3 \\
\hline $\begin{array}{l}\text { 3. I felt that I could not shake off } \\
\text { the blues even with help from } \\
\text { my family or friends. }\end{array}$ & 0 & 1 & 2 & 3 \\
\hline $\begin{array}{l}\text { 4. I felt I was just as good as } \\
\text { other people. }\end{array}$ & 0 & 1 & 2 & 3 \\
\hline $\begin{array}{l}\text { 5. I had trouble keeping my mind } \\
\text { on what I was doing. }\end{array}$ & 0 & 1 & 2 & 3 \\
\hline 6. I felt depressed. & 0 & 1 & 2 & 3 \\
\hline $\begin{array}{l}\text { 7. I felt that everything I did was } \\
\text { an effort. }\end{array}$ & 0 & 1 & 2 & 3 \\
\hline 8. I felt hopeful about the future. & 0 & 1 & 2 & 3 \\
\hline $\begin{array}{l}\text { 9. I thought my life had been a } \\
\text { failure. }\end{array}$ & 0 & 1 & 2 & 3 \\
\hline 10. I felt fearful. & 0 & 1 & 2 & 3 \\
\hline 11. My sleep was restless. & 0 & 1 & 2 & 3 \\
\hline 12. I was happy. & 0 & 1 & 2 & 3 \\
\hline 13. I talked less than usual. & 0 & 1 & 2 & 3 \\
\hline 14. I felt lonely. & 0 & 1 & 2 & 3 \\
\hline 15. People were unfriendly. & 0 & 1 & 2 & 3 \\
\hline
\end{tabular}




\begin{tabular}{|c|c|c|c|c|}
\hline & \multicolumn{4}{|c|}{ Last Week } \\
\hline DURING THE PAST WEEK: & $\begin{array}{l}\text { Rarely or } \\
\text { none of } \\
\text { the time }\end{array}$ & $\begin{array}{l}\text { Some or a } \\
\text { little of the } \\
\text { time }\end{array}$ & $\begin{array}{l}\text { Occasionally } \\
\text { or a moderate } \\
\text { amount of } \\
\text { time }\end{array}$ & $\begin{array}{l}\text { Most or all of } \\
\text { the time }\end{array}$ \\
\hline & $\begin{array}{c}\text { (less than } 1 \\
\text { day) }\end{array}$ & (1-2 days) & (3-4 days) & (5-7 days) \\
\hline 16. I enjoyed life. & 0 & 1 & 2 & 3 \\
\hline 17. I had crying spells. & 0 & 1 & 2 & 3 \\
\hline 18. I felt sad. & 0 & 1 & 2 & 3 \\
\hline 19. I felt that people dislike me. & 0 & 1 & 2 & 3 \\
\hline 20. I could not get "going". & 0 & 1 & 2 & 3 \\
\hline
\end{tabular}




\section{Appendix G}

1. How old are you?

2. What is your race?
a. American Indian/Alaskan Native
b. Asian American
c. Black
d. Caucasian
e. Native Hawaiian/Pacific Islander
f. Other:

3. What is your ethnicity?
a. Hispanic/Latino
b. Non-Hispanic/Non-Latino

4. What is your marital status?
a. Divorced
b. Married
c. Separated
d. Single
e. Widowed

5. How many years of education do you have?

6. Have you ever been incarcerated (i.e., served time at a jail or prison)?
a. Yes
b. No 